\title{
Filling-in of near-infrared solar lines by terrestrial fluorescence and other geophysical effects: simulations and space-based observations from SCIAMACHY and GOSAT
}

\author{
J. Joiner ${ }^{1}$, Y. Yoshida ${ }^{2}$, A. P. Vasilkov ${ }^{2}$, E. M. Middleton ${ }^{1}$, P. K. E. Campbell ${ }^{3}$, Y. Yoshida $^{4}$, A. Kuze , and L. A. Corp $^{6}$ \\ ${ }^{1}$ NASA Goddard Space Flight Center, Greenbelt, MD, USA \\ ${ }^{2}$ Science Systems and Applications, Inc., 10210 Greenbelt, Rd., Ste 400, Lanham, MD, USA \\ ${ }^{3}$ University of Maryland, Baltimore County, Joint Center for Environmental Technology (UMBC-JCET), \\ Baltimore, MD, USA \\ ${ }^{4}$ National Institute for Environmental Studies (NIES), Tsukuba-City, Ibaraki, Japan \\ ${ }^{5}$ Japan Aerospace Exploration Agency (JAXA), Tsukuba-City, Ibaraki, Japan \\ ${ }^{6}$ Sigma Space Corp., Lanham, MD, USA
}

Correspondence to: J. Joiner (joanna.joiner@ nasa.gov)

Received: 8 November 2011 - Published in Atmos. Meas. Tech. Discuss.: 6 January 2012

Revised: 19 March 2012 - Accepted: 11 April 2012 - Published: 24 April 2012

\begin{abstract}
Global mapping of terrestrial vegetation fluorescence from space has recently been accomplished with high spectral resolution $(v / \Delta v>35000)$ measurements from the Japanese Greenhouse gases Observing SATellite (GOSAT). These data are of interest because they can potentially provide global information on the functional status of vegetation including light-use efficiency and global primary productivity that can be used for global carbon cycle modeling. Quantifying the impact of fluorescence on the $\mathrm{O}_{2}-\mathrm{A}$ band is important as this band is used for photon pathlength characterization in cloud- and aerosol-contaminated pixels for trace-gas retrievals including $\mathrm{CO}_{2}$. Here, we examine whether fluorescence information can be derived from space using potentially lower-cost hyperspectral instrumentation, i.e., more than an order of magnitude less spectral resolution $(v / \Delta v \sim 1600)$ than GOSAT, with a relatively simple algorithm. We discuss laboratory measurements of fluorescence near one of the few wide and deep solar Fraunhofer lines in the long-wave tail of the fluorescence emission region, the calcium (Ca) II line at $866 \mathrm{~nm}$ that is observable with a spectral resolution of $\sim 0.5 \mathrm{~nm}$. The filling-in of the Ca II line due to additive signals from various atmospheric and terrestrial effects, including fluorescence, is simulated.
\end{abstract}

We then examine filling-in of this line using the SCanning Imaging Absorption spectroMeter for Atmospheric CHartographY (SCIAMACHY) satellite instrument. In order to interpret the satellite measurements, we developed a general approach to correct for various instrumental artifacts that produce false filling-in of solar lines in satellite measurements. The approach is applied to SCIAMACHY at the $866 \mathrm{~nm} \mathrm{Ca}$ II line and to GOSAT at 758 and $770 \mathrm{~nm}$ on the shoulders of the $\mathrm{O}_{2}$-A feature where there are several strong solar Fraunhofer lines that are filled in primarily by vegetation fluorescence. Finally, we compare temporal and spatial variations of SCIAMACHY additive signals with those of GOSAT and the Enhanced Vegetation Index (EVI) from the MODerate-resolution Imaging Spectroradiometer (MODIS). Although the derived additive signals from SCIAMACHY are extremely weak at $866 \mathrm{~nm}$, their spatial and temporal variations are consistent with chlorophyll $a$ fluorescence or another vegetation-related source. We also show that fillingin occurs at $866 \mathrm{~nm}$ over some barren areas, possibly originating from luminescent minerals in rock and soil. 


\section{Introduction}

Fluorescence from terrestrial vegetation has been measured in the laboratory and with ground- and aircraft-based instruments for several decades (see e.g., the review of Meroni et al., 2009, and the many references therein). More recently, it has been demonstrated that fluorescence information can also be derived from satellite passive sensors measuring backscattered sunlight at wavelengths near the $\mathrm{O}_{2}$-A band absorption feature. It is important to quantify the impact of fluorescence on atmospheric absorption bands, such as the $\mathrm{O}_{2}$-A band, that are used for cloud- and aerosol-characterization for other trace-gas retrievals, including $\mathrm{CO}_{2}$ (e.g., Frankenberg et al., 2011a). These fluorescence measurements, particularly with global coverage from satellites, are of interest in their own right because the signal originates from the core complexes of the photosynthetic machinery where energy conversion of absorbed photosynthetically active radiation (PAR) occurs. Chlorophyll fluorescence measurements therefore may provide a means to estimate global instantaneous vegetation carbon-related processes, such as those important to precision farming, forest management, and assessment of the terrestrial carbon budget including gross primary productivity (GPP) (e.g., Campbell et al., 2008; Damm et al., 2010; Frankenberg et al., 2011b).

Fluorescence in vegetation occurs because a portion of the sunlight absorbed by chlorophyll cannot be used for carbon fixation. While most of this unused energy is given off as heat, a small fraction is re-emitted as fluorescence at longer wavelengths (lower energy) with respect to the excitation wavelength. The far-red and red fluorescence generally occurs as a convolution of broad band emission with two peaks at 685 and $740 \mathrm{~nm}$, respectively, as shown in Fig. 1 (e.g., Meroni et al., 2009; Corp et al., 2003, 2006). Many studies have shown that in high light conditions (i.e., in the late morning and early afternoon when many satellite measurements are made) and when plants are under stress, fluorescence is correlated with photosynthesis and light use efficiency (LUE) (e.g., Flexas et al., 2002; Louis et al., 2005; Meroni et al., 2008; van der Tol et al., 2009; Zarco-Tejada et al., 2009; Daumard et al., 2010; Amoros-Lopez et al., 2008). Other research has indicated that chlorophyll fluorescence supplies information content about photosynthetic function that is complementary to reflectance-based spectral vegetation indices including the Normalized Difference Vegetation Index (NDVI) and the Enhanced Vegetation Index (EVI), linked to chlorophyll content, and the Photochemical Reflectance Index (PRI), related to changes in xanthophyll cycle pigments (Meroni and Colombo, 2006; Middleton et al., 2008, 2009; Rascher et al., 2009; Meroni et al., 2008; Daumard et al., 2010; Guanter et al., 2007; Zarco-Tejada et al., 2009; Joiner et al., 2011; Frankenberg et al., 2011b; Guanter et al., 2012).

Space-based measurement of solar-induced chlorophyll fluorescence is challenging, because its signal (typically

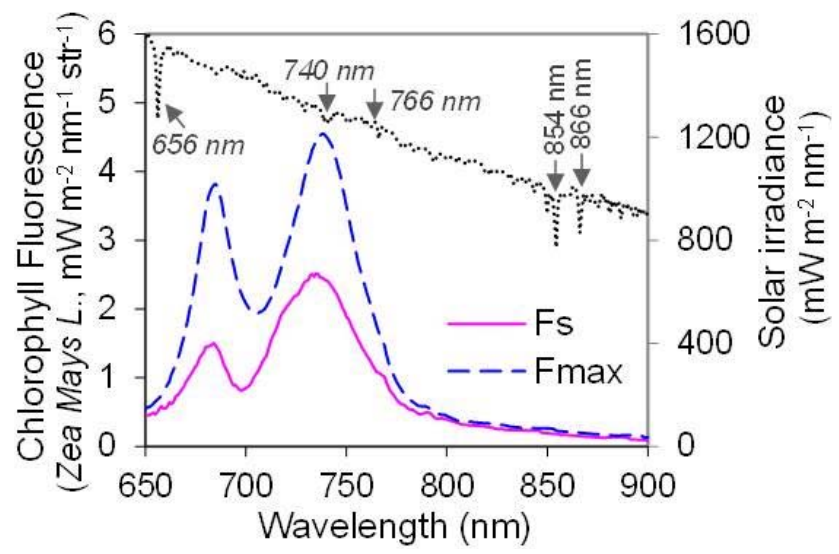

Fig. 1. Measured fluorescence spectra of excised corn leaves (Zea Mays L.) in the laboratory, with simulated solar illumination at full mid-day sun intensity as measured below a long-pass filter blocking wavelengths longer than $665 \mathrm{~nm}$, showing maximum fluorescence $\left(F_{\max }\right)$ after $5 \mathrm{~min}$. of dark adaptation, steady state fluorescence ( $F_{\mathrm{S}}$, achieved in less than $0.5 \mathrm{~min}$ after illumination), and a sample solar spectrum from Thuillier et al. (2003, 2004).

$1-5 \%$ at red and far-red wavelengths) is small as compared with the much larger reflectance signal. Ground- and aircraftbased approaches have made use of the dark and spectrallywide $\mathrm{O}_{2}$-A $(\sim 760 \mathrm{~nm})$ and $\mathrm{O}_{2}$-B $(\sim 690 \mathrm{~nm})$ atmospheric features to detect the weak fluorescence signal (see e.g., Meroni et al., 2009). Deep solar Fraunhofer lines have also been used to detect fluorescence from vegetation using airborne and ground-based sensors. Initial studies (e.g., Plascyk and Gabriel, 1975; McFarlane et al., 1980; Watson, 1981; Sioris et al., 2003) focused on lines shortward of the red edge $(\sim 700 \mathrm{~nm})$ where the terrestrial surface reflectivity is relatively low. More recently, Joiner et al. (2011), Frankenberg et al. (2011b), and Guanter et al. (2012) focused on longerwavelength solar Fraunhofer lines that can be observed with space-based instruments such as the currently operational GOSAT. They showed that fluorescence can be detected using Fraunhofer lines off the far-red chlorophyll $a$ fluorescence peak even when the surface is relatively bright.

Here we build on that work by examining the possibility of making fluorescence measurements from space with lower spectral resolution instrumentation as compared with the GOSAT interferometer or similar instruments. If this can be demonstrated, then low cost instrumentation can potentially be used for space- and air-borne measurements with a relatively simple retrieval algorithm, i.e., one that does not require complex atmospheric correction. Of the wide and deep solar lines shown in Fig. 1, we focus on the $866 \mathrm{~nm}$ Ca II solar Fraunhofer line. This is the only line with negligible contamination from atmospheric water vapor capable of detecting fluorescence at spectral resolutions of about $0.5 \mathrm{~nm}$. We first examine laboratory measurements of fluorescence at the long-wavelength tail of the $740 \mathrm{~nm}$ feature near $866 \mathrm{~nm}$. 
We then simulate the potential filling-in of this line from atmospheric effects, namely vibrational and rotational Raman scattering, as well as from fluorescence and high temperature emitters such as fires and volcanoes. Finally, we make use of unique spectral radiance measurements from the SCanning Imaging Absorption spectroMeter for Atmospheric CHartographY (SCIAMACHY) instrument aboard the European Space Agency (ESA) Environmental satellite (EnviSat) encompassing the $\mathrm{Ca}$ II line at $866 \mathrm{~nm}$. SCIAMACHY observations are used to retrieve an additive signal that fills in the Ca II line. This is clearly not an optimal wavelength region for measuring fluorescence owing to the extreme weakness of the signal; instrumental artifacts could easily overwhelm a fluorescence signal. However, although not optimized for detecting fluorescence, SCIAMACHY can be used for an exploratory study.

An integral part of this work is to introduce a general approach to correct for a number of different instrumental artifacts that produce false filling-in signals and thus bias fluorescence retrievals. The methodology is applied to both SCIAMACHY and GOSAT data and is generalizable to other instruments. This methodology improves the accuracy of the results reported in the initial GOSAT study of Joiner et al. (2011) and enables the use of more data as compared with the approach of Frankenberg et al. (2011b), thereby potentially increasing the fidelity of GOSAT data.

The paper is organized as follows: we discuss laboratory fluorescence measurements at the long-wavelength tail of the chlorophyll $a$ fluorescence spectrum in Sect. 2. Section 3 describes the satellite observations used here. Simulations of the satellite-observed Ca II line-filling at $866 \mathrm{~nm}$ from atmospheric and terrestrial effects including fluorescence are given in Sect. 4. In this section, we also examine the impact of clouds and aerosol on fluorescence retrievals. The details of our retrieval approach, including methodology to correct for instrumental artifacts, are provided in Sect. 5. We show maps of monthly-mean derived additive signals from $866 \mathrm{~nm}$ Ca II line-filling and a seasonal climatology using more than $8 \mathrm{yr}$ of SCIAMACHY data in Sect. 6. In this section, we also compare and contrast temporal and spatial variations of the additive signals (retrieved from both SCIAMACHY and GOSAT) with the MODIS EVI. Conclusions are given in Sect. 7.

\section{Laboratory measurements of fluorescence at wavelengths $>850 \mathrm{~nm}$}

As the derived additive signals at $866 \mathrm{~nm}$ shown in Sect. 6 appear to be consistent with a vegetation source, namely fluorescence, here we discuss laboratory measurements of vegetation fluorescence made at similar wavelengths. Laboratory instruments using light-induced pulses have focused on the red and far-red fluorescence emission peaks and not the far-red/NIR emission tail in diagnostic measurements. This is true for laser-induced lab and field measurements as well. Detectors are typically chosen to be affordable and are therefore usually limited in spectral range. Consequently, very little information is available on the NIR tail region beyond about $800 \mathrm{~nm}$.

Figure 1 displays fluorescence measurements of corn leaves acquired in our laboratory using polychromatic excitation at wavelengths shorter than $665 \mathrm{~nm}$ (Oriel 91160A and Oriel 81080) after a five minute dark adaptation of the samples. Chlorophyll fluorescence levels decrease significantly from the initial dark-adapted maximum $\left(F_{\max }\right)$ to the steady state $\left(F_{\mathrm{S}}\right)$ in $15-20 \mathrm{~s}$, after which they remain relatively constant over time. Here, we show that $F_{\max }$ and $F_{\mathrm{s}}$ levels in the red and far-red peaks vary significantly, but are much lower in value and do not differ significantly in the emission tails (e.g., at 656 and $854-866 \mathrm{~nm}$ ). At $866 \mathrm{~nm}$, the measured signal is of the order of $0.1-0.2 \mathrm{~mW} \mathrm{~m}^{-2} \mathrm{~nm}^{-1} \mathrm{sr}^{-1}$.

Amoros-Lopez et al. (2008) similarly report spectral measurements from $650-850 \mathrm{~nm}$ showing a small amount of fluorescence $\left(\sim 0.1 \mathrm{~mW} \mathrm{~m}^{-2} \mathrm{~nm}^{-1} \mathrm{sr}^{-1}\right)$ at $850 \mathrm{~nm}$ when illuminated by sunlight through a filter that restricts excitation to wavelengths shorter than about $600 \mathrm{~nm}$ (i.e., not full ambient intensity at leaf level). They also measured a diurnal cycle of fluorescence for wavelengths up to $800 \mathrm{~nm}$ using artificial illumination in a setup similar to that described above. Their results show very little difference in fluorescence measured at 10:00 (close to the SCIAMACHY local overpass time) and 12:00 (closer to the GOSAT local overpass time) for wavelengths between 770 and $800 \mathrm{~nm}$. Fluorescence at 14:00 was slightly lower (by $\sim 15 \%$ ) as compared with noon. Other measurements (e.g., Chappelle and Williams, 1987; Rosema et al., 1991; Edner et al., 1994; Saito et al., 1998) suggest that the long-wave tail of the chlorophyll $a$ fluorescence emissions and perhaps fluorescence from other compounds such as vitamin $\mathrm{K}_{1}$ (Chappelle et al., 1984) may produce a measurable signal at wavelengths beyond $800 \mathrm{~nm}$.

We did not, however, detect a resolvable fluorescence signal with respect to instrument signal-to-noise at $866 \mathrm{~nm}$ using a Fluorolog ${ }^{\circledR} 3$ spectrofluorometer with monochromatic excitation. Excitation wavelengths ranging from the ultraviolet through the visible were used. One possible explanation is that fluorescence at the long wavelength tail of the fluorescence spectrum may be higher when induced by fullspectrum sunlight as compared with a monochromatic source or in a partially-illuminated scenario. Measurements have shown that the excitation efficiency of chlorophyll fluorescence is high in the blue and ultraviolet (UV) with a minimum around $550 \mathrm{~nm}$ and another peak of high efficiency beyond about $650 \mathrm{~nm}$ (Chappelle and Williams, 1987; Rosema et al., 1991; Middleton et al., 2008). 


\section{Satellite observations}

\subsection{SCIAMACHY}

SCIAMACHY is a grating spectrometer that measures transmitted, reflected, and scattered sunlight in both limb- and nadir-viewing geometries from ultraviolet to near-infrared wavelengths $(212-2386 \mathrm{~nm})$ in eight separate channels. It was launched on the EnviSat platform in February 2002 into a sunsynchronous orbit with a descending node equator crossing time near 10:00 LT. The instrument can make measurements in a number of different modes (e.g., Lichtenberg et al., 2006). In addition to Earth views in the limb and nadir, it can operate in a solar or lunar occultation mode. It also measures the solar irradiance. In this work, we primarily use channel 5 that covers wavelengths between 773 and $1063 \mathrm{~nm}$ at a spectral resolution of $0.54 \mathrm{~nm}$. The signalto-noise ratio (SNR) for nadir measurements in this channel is between 1000 and 10000 (Gottwalk et al., 2006) and the ground footprint size is approximately $30 \mathrm{~km}$ in the along track direction and about $60 \mathrm{~km}$ in the cross-track direction for latitudes between $60^{\circ} \mathrm{N}$ and $60^{\circ} \mathrm{S}$. We also examined spectra in channel 4 that covers $595-812 \mathrm{~nm}$ at $0.48 \mathrm{~nm}$ spectral resolution, but do not include any results from that channel in this work.

We processed raw SCIAMACHY level 1B data with the SciaL1c command-line tool software package (DLR, 2006). Using this package, we applied all available corrections and calibrations. Although the corrections do an excellent job of removing most artifacts that produce false filling-in of solar Fraunhofer lines, we found it necessary to further account for the remaining effects as discussed in Sect. 5. In Appendix A, we give a brief overview of the effects. More details can be found in Lichtenberg et al. (2006).

\subsection{GOSAT}

GOSAT is a satellite mission designed to monitor the global distribution of the greenhouse gases $\mathrm{CO}_{2}$ and $\mathrm{CH}_{4}$ (Yokota et al., 2009). Jointly developed by the Japanese Ministry of the Environment (MOE), the National Institute for Environmental Studies (NIES), and the Japanese Aerospace Exploration Agency (JAXA), GOSAT was launched on 23 January 2009 into a sun-synchronous orbit. It has a descending node equatorial crossing time near 13:00 LT and a 3 day repeat cycle. GOSAT has two instrument packages: (1) the Thermal And Near-infrared Sensor for carbon ObservationFourier Transform Spectrometer (TANSO-FTS) (Kuze et al., 2009) measures backscattered solar radiation in three shortwave infrared (SWIR) regions, referred to as "bands", centered at $0.76,1.6$, and $2.0 \mu \mathrm{m}$ with a nadir ground footprint of $10.5 \mathrm{~km}$ diameter and (2) the Cloud and Aerosol Imager (CAI) contains four bands at $0.38,0.67,0.87$, and $1.6 \mu \mathrm{m}$ and footprints between 0.5 and $1.5 \mathrm{~km}$.
Joiner et al. (2011), Frankenberg et al. (2011b), and Guanter et al. (2012) retrieved chlorophyll fluorescence using TANSO-FTS band 1 . This band extends from approximately 758 to $775 \mathrm{~nm}$ with a resolving power $(v / \Delta v)$ of $>35000$. The SNR for this band is $>300$ for a typical scene radiance.

There are also instrumental effects that can distort GOSAT spectra to produce a false filling-in of Fraunhofer lines. These include non-linearity from the analog-to-digital converter (ADC) (Kuze et al., 2011b) and the analog filter circuit in band 1 that can lead to effects such as a zero-level offset (Frankenberg et al., 2011b). In addition, calibration drift (Kuze et al., 2011a) may produce errors and drift in the absolute values of the derived additive signal. The latest available version (v130) of the level 1b data addresses some, but not all of these problems. Future versions will provide more corrections for these non-linearities. Only a limited amount of v130 data is currently available. Therefore, here we use a previous version of level $1 \mathrm{~b}$ data (v050-v100) with an approach to account for instrumental artifacts that produce false filling-in as described below.

\subsection{MODIS Vegetation indices}

Below, we compare satellite-derived fluorescence with the Enhanced Vegetation Index (EVI) (Huete et al., 2002), a popular vegetation reflectance-based index that indicates relative greenness and is used to infer photosynthetic function. The EVI, derived from the MODIS instrument, can be found in the "Vegetation Indices 16-Day L3 Global $1 \mathrm{~km}$ " (MOD13A2) data set. We use data from the Aqua MODIS, acquired in the early afternoon, exclusively here for direct comparisons with 2009 GOSAT results and averaged over the period August 2002 through June 2011 for climatological comparisons with SCIAMACHY. The Aqua satellite has an ascending node equator crossing near 13:30 LT. Although these data have been cloud-filtered and corrected for aerosolcorruption effects, we followed the methodology of Xu et al. (2011) to further remove residual atmospheric corruption in order to produce the best possible signals from vegetation.

\section{Simulated filling-in at $866 \mathrm{~nm}$}

Here, we simulate the effects of additive signals such as fluorescence as well as rotational- and vibration-Raman scattering on space-based observations of the $\mathrm{Ca}$ II line near $866 \mathrm{~nm}$. We use the so-called KPNO2010 high spectral resolution solar irradiance reference spectrum (Chance and $\mathrm{Ku}-$ rucz, 2010) for these simulations and convolve the spectrum with triangular instrument line shape functions having different values of the full-width half-maximum (FWHM) including one similar to SCIAMACHY. 


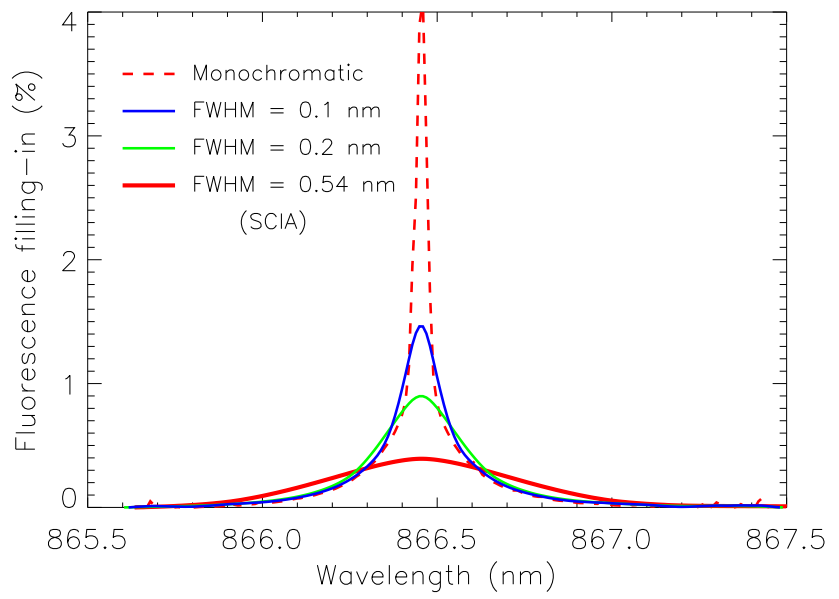

Fig. 2. Simulated spectral filling-in around the Ca II solar line from an additive signal of $0.2 \mathrm{~mW} \mathrm{~m}^{-2} \mathrm{~nm}^{-1} \mathrm{sr}^{-1}, \mathrm{SZA}=40^{\circ}$ nadir, and surface reflectivity $=0.3$ (RRS not included) for different instrument resolutions (triangular slit function) with full-width half-maximum (FWHM) as indicated including that of SCIAMACHY (SCIA).

\subsection{Fluorescence and other additive signals}

Figure 2 shows simulated filling-in of the $866 \mathrm{~nm}$ Ca II solar line for a spectrally constant additive signal of $0.2 \mathrm{~mW} \mathrm{~m}^{-2} \mathrm{sr}^{-1} \mathrm{~nm}^{-1}$, for several different spectral resolutions including the limit at the native $0.01 \mathrm{~nm}$ resolution of the Chance and Kurucz (2010) spectrum (denoted monochromatic in the figure). Because Rayleigh optical thickness is low at these wavelengths, we did not include atmospheric scattering in these simulations. The surface is treated as Lambertian with an equivalent reflectivity. The filling-in at SCIAMACHY resolution is small $(<1 \%)$. However, modest increases in spectral resolution will increase the filling-in.

Figure 3 shows the surface reflectivity dependence of the simulated filling-in of the $866 \mathrm{~nm} \mathrm{Ca}$ II line for the same signal $\left(0.2 \mathrm{~mW} \mathrm{~m}^{-2} \mathrm{~nm}^{-1} \mathrm{sr}^{-1}\right)$ and spectral resolutions as in Fig. 2. The surface reflectivity dependence is significant at low surface reflectivities. However, the dependence flattens out at values typical of vegetated land $(>\sim 0.25)$.

Note that the above results hold for any type of additive signal including fluorescence from sources in vegetation or minerals. Another potential source of additive signal is radiation emitted from fires or volcanoes. Using the Planck function, we estimate that the radiance from a source at $1000 \mathrm{~K}$ will produce a signal of the order of $15 \mathrm{~mW} \mathrm{~m}^{-2} \mathrm{~nm}^{-1} \mathrm{sr}^{-1}$ at $866 \mathrm{~nm}$ and $\sim 3 \mathrm{~mW} \mathrm{~m}^{-2} \mathrm{~nm}^{-1} \mathrm{sr}^{-1}$ at $770 \mathrm{~nm}$. If such a source filled a SCIAMACHY or GOSAT field-of-view, it would certainly be detectable. However, flaming portions of fires and sources of hot gas and lava from volcanoes are most likely to fill only a small fraction of the relatively large GOSAT or SCIAMACHY footprints. Never-the-less, fires and volcanoes should be considered as potential sources of solar line filling at far-red and NIR wavelengths. Reducing

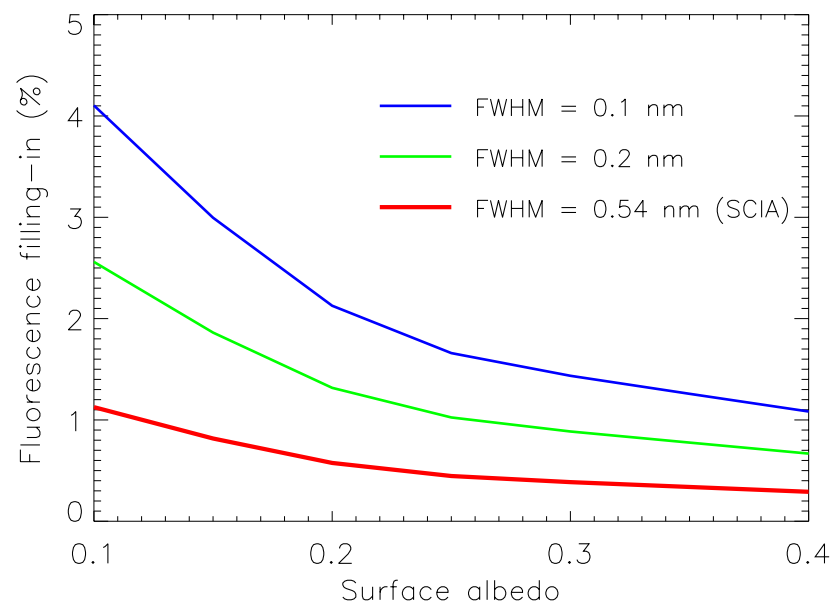

Fig. 3. Filling-in due to an additive signal of $0.2 \mathrm{~mW} \mathrm{~m}^{-2} \mathrm{~nm}^{-1}$ $\mathrm{sr}^{-1}, \mathrm{SZA}=20^{\circ}$, and nadir as a function of surface reflectivity for different instrument spectral resolutions.

temperatures to $<\sim 650 \mathrm{~K}$ renders the filling-in signals undetectable at the wavelengths and resolutions of SCIAMACHY and GOSAT.

\subsection{Rotational-Raman scattering}

We computed the filling-in of the $866 \mathrm{~nm}$ Ca II line due to rotational-Raman scattering (RRS) using the scalar Linearized Discrete Ordinate Radiative Transfer code (LIDORTRRS) of Spurr et al. (2008). Figure 4 shows the filling-in as in Fig. 2 but from rotational-Raman scattering (RRS) only. Although the amount of atmospheric scattering is relatively small at these wavelengths, the RRS filling-in is apparent owing to the large depth of this solar line as similarly shown by Joiner et al. (2011) for the K I line at $770 \mathrm{~nm}$. The spectral signature is very similar to that of line filling from a spectrally flat additive signal. The filling-in owing to RRS is about a factor of 6 less than that due to an additive signal of $0.2 \mathrm{~mW} \mathrm{~m}^{-2} \mathrm{~nm}^{-1} \mathrm{sr}^{-1}$ at SCIAMACHY resolution. This factor increases somewhat at higher spectral resolutions.

Figure 5 shows that the RRS filling-in dependence on surface reflectivity is relatively flat for reflectivities $>\sim 0.3$. There is a small but significant dependence on both surface pressure and solar zenith angle (SZA). Figure 6 shows the SZA dependence in more detail as well as the dependence on satellite view zenith angle (VZA) and surface pressure. The SZA dependence is relatively small for $\mathrm{SZA}<60^{\circ}$, but increases rapidly for greater angles. The VZA dependence is small for typical angles viewed by SCIAMACHY.

\subsection{Vibrational-Raman scattering}

Vibrational Raman scattering (VRS) is commonly neglected in UV and visible retrieval algorithms as it is small compared with rotational-Raman scattering (RRS) (Burrows et al., 


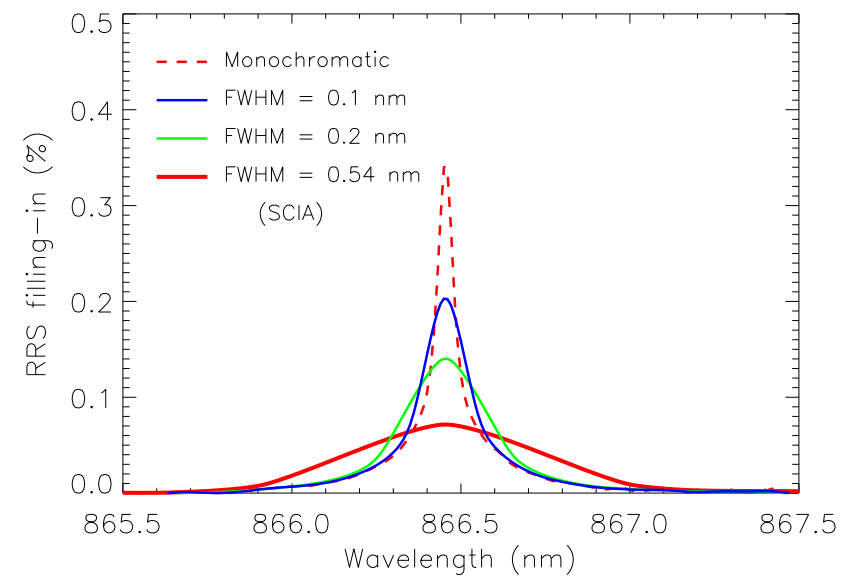

Fig. 4. Simulated filling-in spectra due to rotational-Raman scattering (RRS) only at $\mathrm{SZA}=40^{\circ}$, nadir, and surface reflectivity $=0.3$ for different instrument spectral resolutions.

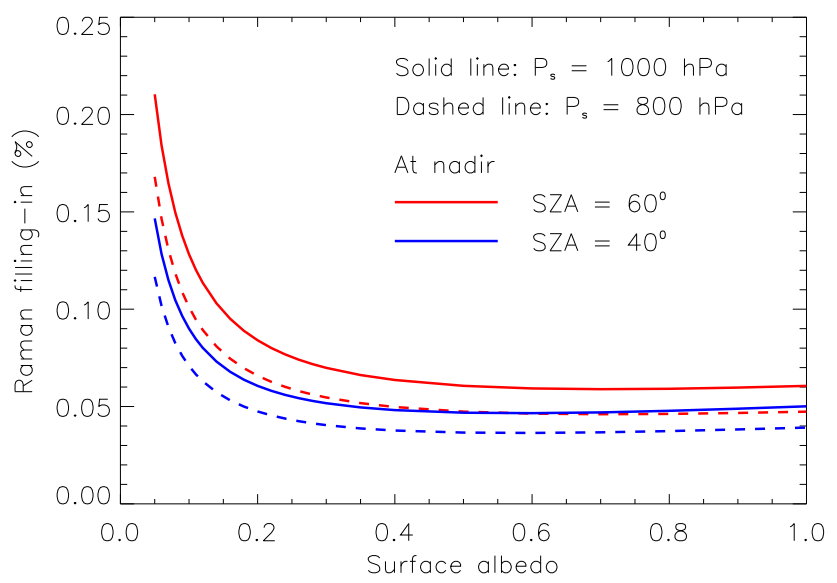

Fig. 5. Filling-in of Ca II line at $866 \mathrm{~nm}$ due to rotational-Raman scattering as a function of surface reflectivity for two solar zenith angles (SZA) and two surface pressures $\left(P_{\mathrm{S}}\right)$ showing simulated difference between low clouds over ocean $(800 \mathrm{hPa})$ and a low lying land area $(1000 \mathrm{hPa})$.

1996). However, the fractional contribution of VRS is larger in the NIR owing to higher values of solar radiation at excitation wavelengths as compared with emission wavelengths. The VRS frequency shifts between excitation and emission are $\Delta v \simeq 2331$ and $1555 \mathrm{~cm}^{-1}$ for $\mathrm{N}_{2}$ and $\mathrm{O}_{2}$, respectively, assuming pure vibrational transitions of the molecules (Heise and Schrotter, 1995). We assessed the VRS contribution to the filling-in of the $866 \mathrm{~nm}$ Ca II Fraunhofer line using the single scattering approximation of the radiative transfer equation. Along with photons only scattered in the atmosphere, we also accounted for photons first reflected from the surface and then scattered in the atmosphere.

Absolute differential Raman cross sections of the vibrational line at $488 \mathrm{~nm}$ at $90^{\circ}$ measured by different authors for $\mathrm{N}_{2}$ vary from $3.3 \times 10^{-31}$ to $5.6 \times 10^{-31} \mathrm{~cm}^{2}$ str- $\mathrm{mol}^{-1}$

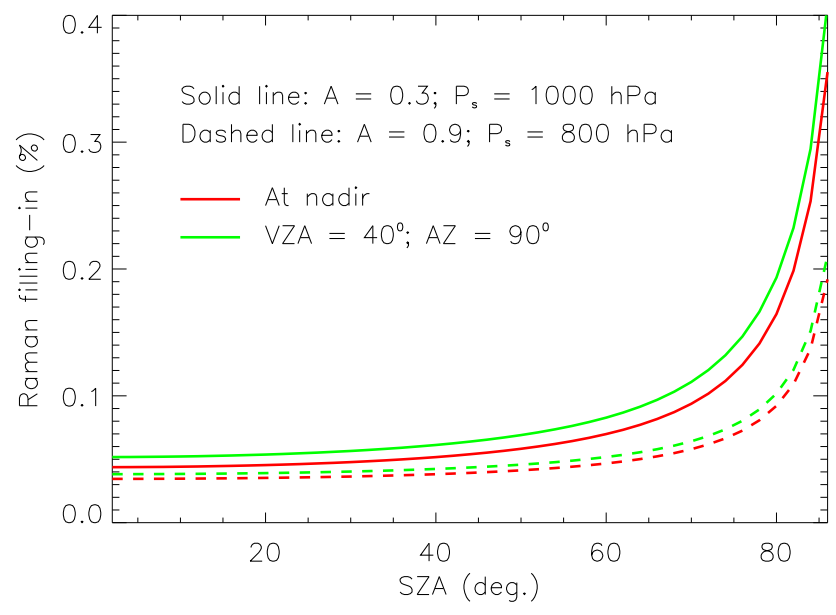

Fig. 6. Filling-in of $\mathrm{Ca}$ II line at $866 \mathrm{~nm}$ due to rotational-Raman scattering as a function of solar zenith angle (SZA) for 2 view zenith angles (VZA) typical of minimum (nadir, $0^{\circ}$ ) and maximum $\left(40^{\circ}\right)$ for SCIAMACHY for a relative azimuth angle (AZ) of $90^{\circ}$.

(Fenner et al., 1973). Here, we use a value of $5.5 \times 10^{-31} \mathrm{~cm}^{2}$ str- $\mathrm{mol}^{-1}$ that is consistent with data from Heise and Schrotter (1995). The ratio of $\mathrm{O}_{2}$ to $\mathrm{N}_{2}$ cross sections at $488 \mathrm{~nm}$ is assumed to be 1.3 (Fenner et al., 1973). We adopt a general form of phase functions for both the unshifted Cabannes line and wavelength shifted VRS lines as suggested by Danichkin et al. (1982). For the central Cabannes line in air, the depolarization ratio for unpolarized light is assumed equal to 0.00734 (Chance and Spurr, 1997). For VRS lines, we use values recommended by Danichkin et al. (1982), i.e., 0.043 and 0.099 for $\mathrm{N}_{2}$ and $\mathrm{O}_{2}$, respectively.

Figure 7 shows the VRS filling-in of the $866 \mathrm{~nm}$ Ca II Fraunhofer line as a function of surface reflectivity. The maximum value of about $0.45 \%$ occurs for a non-reflecting surface. VRS filling-in rapidly decreases with increasing surface reflectivity. For typical values of surface reflectivity over land ( $>0.2$ ), the filling-in only weakly depends on surface reflectivity and does not exceed $0.02 \%$ for SZA $<60^{\circ}$. Therefore, we neglect VRS in the remainder of this study.

\section{Retrieval methodology}

\subsection{Fitting windows}

The use of solar Fraunhofer lines substantially simplifies a space-based retrieval of $F_{\mathrm{S}}$ as compared with the $\mathrm{O}_{2}$ A band as described by Joiner et al. (2011) and Frankenberg et al. (2011a); atmospheric correction is unnecessary as long as observations are made at wavelengths not affected by atmospheric absorption. Joiner et al. (2011) used the potassium (K) I line near $770 \mathrm{~nm}$ to derive an additive signal using GOSAT's TANSO-FTS. This line falls between several weak $\mathrm{O}_{2}$ lines and can be observed in relative 


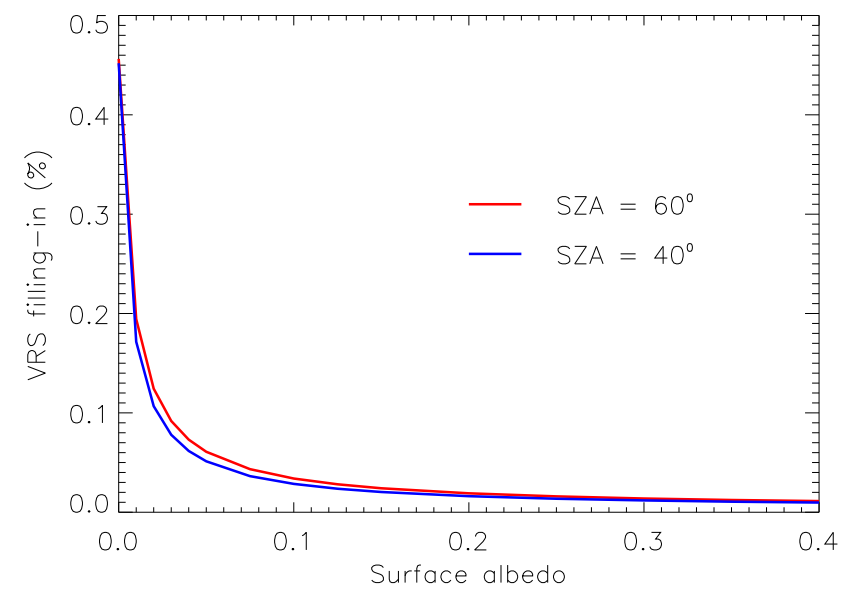

Fig. 7. Filling-in of Ca II line at $866 \mathrm{~nm}$ due to vibrational-Raman scattering (VRS) as a function of surface reflectivity for 2 solar zenith angles (SZA).

isolation with GOSAT's high spectral resolution. Here, we use the same GOSAT fitting window as Joiner et al. (2011) $(769.90-770.25 \mathrm{~nm})$. We use a second fitting window between 758.45 and $758.85 \mathrm{~nm}$. Our fitting windows are similar to, though more narrow than, those used by Frankenberg et al. (2011b) and Guanter et al. (2012). While the use of broader fitting windows that include more Fraunhofer lines may potentially improve the signal-to-noise ratio of the retrievals, it may also require the retrieval of additional parameters such as those that account for the wavelength dependence of surface reflectivity and fluorescence. We have chosen here a conservative approach that utilizes narrow windows that contain the strongest Fraunhofer lines, although the approach can be extended to wider fitting windows. Further optimization of fitting windows is beyond the scope of this work but may be the focus of a future study.

Of the solar lines shown in Fig. 1 (656, 850, 854, $866 \mathrm{~nm})$, only the $866 \mathrm{~nm} \mathrm{Ca}$ II line is relatively free of contamination by atmospheric water vapor absorption. We attempted to retrieve additive signals using all of these lines including the $H \alpha$ line near $656 \mathrm{~nm}$ in SCIAMACHY channel 4. We found that it was difficult to disentangle the filling-in signal from water vapor absorption. Therefore, in the remainder of this work, we focus solely on deriving an additive signal using the $866 \mathrm{~nm}$ Ca II solar line from SCIAMACHY with the spectral band $863.5-868.5 \mathrm{~nm}$.

\subsection{General approach}

We use a variation of the approach implemented by Joiner et al. (2011) to jointly retrieve a reflectivity-related parameter $K$ and an additive signal. We denote the generic additive signal henceforth as " $\bar{F}$ ". We use the above-mentioned spectral fitting windows with the following simplified model for the observed Earth spectral radiance $\boldsymbol{I}(\lambda)$ that assumes negligible atmospheric absorption and scattering (Joiner et al., 2011):

$\boldsymbol{I}(\lambda)=K \boldsymbol{E}(\lambda)^{*}+\bar{F}$,

where $\boldsymbol{E}(\lambda)^{*}$ is a reference spectrum ideally containing no filling-in from the source of interest. We note that if the reference spectrum contains filling-in from other sources, the retrieved value will reflect a residual additive signal from sources not present in the reference.

As in Joiner et al. (2011), we assume no wavelength dependence of $\bar{F}$ over our relatively small fitting windows. We fit both constant and linear in wavelength coefficients for $K$ (i.e., $K=K_{0}+K_{1}\left[\lambda-\lambda_{0}\right]$ ) for the larger SCIAMACHY fitting window, but only a constant for the smaller GOSAT windows. The spectral dependence of atmospheric, cloud, and aerosol scattering is essentially constant over the relatively small narrow fitting windows used, so the neglect of it will have an insignificant effect on the retrieval of $\bar{F}$. Similarly, calibration of the reference spectrum $E(\lambda)^{*}$ does not affect the derived value of $\bar{F}$, since any offset between the reference and observed spectra is absorbed in the parameter $K$. An error in absolute calibration of $\boldsymbol{I}(\lambda)$, however, will produce an error in $\bar{F}$.

Similar to the approach of Joiner et al. (2011), we use a standard weighted least squares fitting procedure. All wavelengths are weighted equally except for a few wavelengths within the GOSAT fitting window that are not used because they are affected by $\mathrm{O}_{2}$ absorption.

\subsection{Use of reference spectra}

The main difference between our approach and that of Joiner et al. (2011) is that we use spectral radiance measurements made over the cloudy ocean as a reference rather than a measured or computed solar irradiance spectrum. No further corrections to observed spectra are made. Our retrieval approach therefore does not require a reference solar spectra. In addition, it is relatively insensitive to errors in the instrument line shape function (ILSF), to the extent that the ILSF is sufficiently stable.

The main criterion for reference spectra used to derive $\bar{F}$ from a terrestrial source is that the reference spectra should represent the spectral shape of a solar Fraunhofer line without filling-in from the terrestrial source. There are several advantages of using cloudy Earth radiance spectra as a reference to derive a terrestrial additive signal as opposed to solar irradiance spectra (measured or computed). Firstly, the use of Earth spectra minimizes the so-called undersampling problem and eliminates errors due to inaccuracy of the assumed instrument line shape function. The undersampling problem and a proposed correction method have been discussed at length by Chance et al. (2005). However, we found that the proposed correction method did not achieve the desired accuracy owing to uncertainties in the instrument line shape function. Because the wavelength shifts are very small 
between ocean reference spectra and the land spectra of interest, problems due to undersampling are essentially eliminated. Corrections used by Joiner et al. (2011), that account for under-sampling when referencing to observed solar spectra slightly shifted in wavelength as compared with Earth spectra, are not necessary.

Secondly, referencing to ocean spectra with similar continuum radiance values allows us to significantly reduce the errors from stray light, dark current, zero-level offset, and other instrumental effects that can produce a false filling-in. These effects should be present in the ocean reference spectra at approximately the same level as in land spectra. Therefore, the effects should be accounted for when deriving a terrestrial additive signal using Eq. (1).

Finally, using ocean spectra at similar radiance levels and SZAs as a reference will implicitly account for some of the filling-in due to RRS. RRS depends upon surface reflectivity as well as the mean pressure of the scattering surface. Here, we are using cloudy ocean data at similar SZAs and continuum radiance values to land spectra. Studies of the so-called optical centroid pressure (approximately, the reflectance-weighted mean pressure) of clouds over ocean at moderate reflectivities typical of vegetated land show that the clouds occur mainly between about 775 and $875 \mathrm{hPa}$ (Joiner et al., 2012). Deep convective and frontal clouds that have lower optical centroid pressures typically occur only at higher Lambertian-equivalent reflectivities $(>\sim 0.6)$. Therefore, the main difference in RRS filling-in between the cloudy ocean and land spectra is due to the different effective surface pressures. As shown in Fig. 5, this difference is small, but not negligible for the expected pressure differences, sometimes leading to negative retrieved values of $\bar{F}$. We must bear this difference in mind when examining our results. For regions with surface pressures higher than about $900 \mathrm{hPa}$, there may be unaccounted - for filling - in due to RRS. However, for high-altitude land regions $(<775 \mathrm{hPa})$ the reference ocean spectra may overestimate RRS filling-in.

Frankenberg et al. (2011b) used a different approach to account for instrumental artifacts; they utilized measurements over Antarctica to develop a parameterization for the false fluorescence produced by the zero-level offset in GOSAT data. They showed generally increasing amounts of false fluorescence with radiance levels with some wiggles and a downturn at the highest radiances in the $\mathrm{S}$ polarization. We found similar features using cloudy ocean data. With our approach, we are able to cover the full range of observed radiance values and see a downturn in the false fluorescence or filling-in at the highest radiance levels also in the $\mathrm{P}$ polarization. Our utilization of cloudy ocean data does not necessitate the use of high SZA data to cover the full range of observed continuum radiance values; filling-in from RRS increases rapidly at high SZAs as shown above, although the imprint of RRS is not obvious in the results of Frankenberg et al. (2011b).
Frankenberg et al. (2011b) discarded GOSAT P polarization data because the errors in that polarization were timedependent. We likewise find such time-dependent errors in both GOSAT (both polarizations) and SCIAMACHY data as shown in Appendix B. Because cloudy ocean data are available year round, we are able to account for these errors and use all data including GOSAT P polarization, thereby significantly reducing the effects of instrumental noise.

In addition, cloudy ocean data span all latitudes. Therefore, we are able to account for instrumental effects that vary systematically with orbital phase; our approach is able to detect and correct for subtle but significant latitudinallydependent artifacts in both GOSAT and SCIAMACHY data. We find that the latitudinal-dependence of these artifacts also varies with season. Further details can be found in Appendix B. Guanter et al. (2012) similarly use data over cloudy ocean to account for the GOSAT zero-level offset, but apparently do not account for latitudinal dependences as we have here.

Here, we binned potential reference spectra according to several criteria discussed below. For each bin, we averaged multiple spectra to produce a composite reference spectrum. To reduce any filling-in signal from the ocean, e.g., from ocean Raman scattering (Vasilkov et al., 2002) or fluorescence, we only use observations with reflectances $>0.2$ for SCIAMACHY. For GOSAT we used only observations with a cloud fraction (derived from the CAI) of $>20 \%$.

\subsubsection{SCIAMACHY binning}

For SCIAMACHY, we binned spectra separately for each of the two primary pixel exposure times and for each scan position within a nadir block according to the continuum radiance value and the wavelength shift (with respect to a fixed solar spectrum). We found that the observed filling-in over ocean sometimes changes abruptly and that it also drifts slowly over time. We therefore compute a set of reference spectra for each day of observations. If the standard deviation of the filling-in over ocean for a given day is high, we eliminate that day from our sample.

We use a bin size of 0.1 for $\rho \cos (\mathrm{SZA})$ (proportional to normalized radiance) where $\rho$ is the reflectance. We found that the wavelength shifts varied systematically with latitude, so binning by both wavelength shift and reflectance implicitly accounts for filling-in features such as RRS that are function of solar zenith angle as well as instrumental artifacts that vary systematically with orbital phase. Because the wavelength shifts vary with time, we compute the daily mean and standard deviation of wavelength shift and use 8 bins with intervals of half the standard deviation of the wavelength shift (typically $\sim 0.007 \mathrm{~nm}$ ). 


\subsubsection{GOSAT binning and additional corrections}

For GOSAT, we used bin sizes of 0.05 for normalized radiance $20^{\circ}$ for latitude, and $0.001 \mathrm{~nm}$ for wavelength shift. We use only data processed with the $\mathrm{H}$ gain range as there are not enough data from the $\mathrm{M}$ range to perform a reliable correction. Therefore, data over the Sahara and in parts of central Australia have not been processed. For GOSAT, we retrieve $\bar{F}$ separately for the $\mathrm{S}$ and $\mathrm{P}$ polarizations (separate corrections applied) and average them. We note small differences in absolute values obtained with the two polarizations. Finally, we apply a correction factor to the radiances to account for instrument degradation as suggested by Kuze et al. (2011a).

\subsection{Cloud filtering}

Because clouds do not alter the spectral structure used to retrieve $\bar{F}$, we can tolerate small to moderate amounts of cloud within our satellite footprints; the main effect of clouds will be to shield a portion of the terrestrial additive signal from satellite view. We remove significantly cloud-contaminated data from our samples by two different methods. For SCIAMACHY, we use the concept of the cloud radiance fraction (CRF). CRF is defined as the fraction of observed radiance that is scattered by cloud particles. The CRF is a convenient quantity for cloud screening, because it can be computed directly for large fields-of-view and collocation with a subpixel imager is not necessary.

The CRF is given by

$\mathrm{CRF}=f_{\mathrm{g}} \frac{I_{\mathrm{cld}}}{I_{\mathrm{obs}}}$,

where $f_{\mathrm{g}}$ is the geometric cloud fraction, and $I_{\mathrm{obs}}$ and $I_{\mathrm{cld}}$ are the observed and bare-cloud (no surface reflection) radiances, respectively. Here we use the so-called mixed Lambertian-Equivalent Reflectivity model to estimate the CRF. In this model, $I_{\text {cld }}$ is set equal to $I_{\text {cld80 }}$, defined as a Lambertian surface with an equivalent reflectivity of 0.8 , and $f_{\mathrm{g}}$ is set equal to an effective cloud fraction $f_{\text {eff }}$ that is derived using the relationship

$I_{\mathrm{obs}}=f_{\mathrm{eff}} I_{\mathrm{cld} 80}+\left(1-f_{\mathrm{eff}}\right) I_{\mathrm{clr}}$,

(e.g., see Stammes et al., 2008, for an overview of the approach that has been used to retrieve the cloud optical centroid pressure at NIR through UV wavelengths). In short, the selection of 0.8 as the cloud reflectivity produces an effective cloud fraction that is generally less than the geometric cloud fraction and represents the fraction of the footprint that does not see the ground. Absorption and/or scattering from beneath a thin cloud is accounted for by the second term in Eq. (3).

Here, we neglect atmospheric scattering as it is very small at $866 \mathrm{~nm}$. To compute $I_{\mathrm{clr}}$, we use the black-sky 16day gridded filled-land surface albedo product from Aqua
MODIS (MOD43B3) at $865 \mathrm{~nm}$ (Lucht et al., 2000). We include only observations with CRF $<10 \%$ in our sample. Uncertainty in the SCIAMACHY absolute calibration relative to that of MODIS cause this check to allow a significant fraction of the data into our sample. Application of more or less stringent limits on cloud contamination within a moderate range did not substantially alter the derived spatial patterns of $\bar{F}$.

We calculated the fraction of a field-of-view for which the satellite does not sense the surface $\left(f_{\text {eff }}\right)$ for various cloud conditions. We can express $f_{\text {eff }}$ as a linear function of the geometrical cloud cover $f_{\mathrm{g}}$, i.e., $f_{\mathrm{eff}}=A \times f_{\mathrm{g}}$, where $A$ is a parameter that depends upon surface and cloud optical properties. For a surface reflectivity of $0.2, A=\sim 0.5$ for a cloud optical thickness $(\tau)$ of 10 (using the $\mathrm{C} 1$ cloud model) and $A=0.75$ for $\tau=20$ at $760 \mathrm{~nm}$ (results will be similar at $866 \mathrm{~nm}$ ). Increasing surface reflectivity to 0.4 gives $A=\sim 0.4$ for $\tau=10$ and $A=0.75$ for $\tau=20$. This implies that in partial cloud cover with typical values of $\tau(\sim 10)$, a significant fraction of the surface is still seen by satellites. For example, in $40 \%$ cloud cover with $\tau<10$ and for surface reflectivities typical of vegetated land, $80 \%$ or more of the surface signal is still seen.

Owing to uncertainty in the absolute calibration of GOSAT, here we use the geometrical cloud fraction derived from the GOSAT CAI. We removed observations with $f_{\mathrm{g}}>40 \%$. Derived spatial and temporal variations of additive signals did not depend substantially on the exact values of the thresholds used here for either GOSAT or SCIAMACHY.

\subsection{Quality control}

To create gridded data sets, we tested different filtering schemes for quality control. For SCIAMACHY, we included all data passing gross quality assurance checks on the fillingin, radiance residuals, and wavelength shifts. These checks remove very few observations. However, we have found evidence that the memory effect, described in Appendix A, produces anomalous filling-in observed near coastlines where radiances can have sharp gradients. To eliminate the affected observations, we apply a filter that first compares a field-of-view continuum radiance with the average of the 15 previously-observed fields-of-view continuum radiances. If the previously-observed average differs from the radiance by more than $15 \%$, that field-of-view is discarded from the sample. This filter eliminated a significant amount of data near coastlines and thus results in somewhat noisier averages in those areas. For GOSAT, we removed outliers $(>2 \sigma)$ separately for $\mathrm{P}$ and $\mathrm{S}$ polarization data as well as for the averaged $\mathrm{P}$ and $\mathrm{S}$ data. 


\subsection{Scaled fluorescence}

When comparing the derived additive signals with vegetation indices, we use a quantity called "scaled-F" (Joiner et al., 2011), defined as the retrieved $\bar{F}$ divided by $\cos (\mathrm{SZA})$. This scaling roughly accounts for variations in $\bar{F}$ due to the incoming (clear-sky) PAR.

\subsection{Uncertainties}

Uncertainties for GOSAT retrievals were calculated by Joiner et al. (2011) using standard error propagation and assuming only random errors (i.e., instrumental noise). Here, we similarly compute errors for SCIAMACHY retrievals using the same assumptions. As discussed in Joiner et al. (2011), errors in scaled-F are proportional to $R / \mathrm{SNR}$, and the relative error in terms of fraction of radiance is inversely proportional to $\mathrm{SNR}$. For $\mathrm{SNR}=1000$, which is consistent with radiance residuals, we obtain a relative error of $0.3 \%$. For $R=0.2$ and 0.4 , we obtained scaled-F errors of 0.37 and 0.75 , respectively. Standard deviations in monthly scaled-F retrievals within gridboxes of $0.5^{\circ} \times 0.5^{\circ}$ are roughly consistent with these expected errors as shown in Appendix C.

However, errors from unaccounted-for systematic instrumental errors can be quite significant. For example, the absolute GOSAT $\bar{F}$ values in this work are smaller (by approximately a factor of 2) than those derived by Joiner et al. (2011), owing to the new corrections applied. Because unaccounted-for systematic errors in SCIAMACHY data could be significant and their magnitudes are unknown, it is difficult to accurately quantify the uncertainties in the derived scaled-F. Many SCIAMACHY observations are available for averaging as compared with GOSAT which helps reduce random errors. However, systematic errors are expected to remain. In addition to residual errors left over from imperfect corrections, the South Atlantic Anomaly (SAA) has been known to affect measurements over South America. However, we find no clear evidence of the effects of the SAA on our results.

Here, we provide standard errors for gridbox averages to indicate uncertainty in the mean values. The number of observations in a $0.5^{\circ} \times 0.5^{\circ}$ gridbox in a month varies from 0 to $\sim 12$. For the $8 \mathrm{yr}$ climatological monthly averages, the number of points in a gridbox thus ranges from 0 to about 100. Therefore, for gridboxes with relatively large numbers of observations, the standard error for the climatological monthly mean can be approximately an order of magnitude less than the standard deviation. Sample global maps of these statistical parameters are shown and further discussed for January and July in Appendix C. We note that these values may still underestimate errors in the derived absolute values of $\bar{F}$ and scaled-F and that theoretical error calculations based on the assumption of random, Gaussian errors may be considered only as a lower limit.

\section{Results and discussion}

\subsection{Spatial variations in scaled-F}

Figure 8 shows retrieved gridded monthly mean scaled-F for July and December 2009 derived from GOSAT at $770 \mathrm{~nm}$ and $758 \mathrm{~nm}$ and from SCIAMACHY at $866 \mathrm{~nm}$. The values from SCIAMACHY at $866 \mathrm{~nm}$ are significantly smaller than those at $770 \mathrm{~nm}$, as would be expected if the signals originate from chlorophyll $a$ fluorescence associated with the declining emission tail throughout the NIR region. GOSAT results are comparable in magnitude and show similar spatial/temporal characteristics as compared with those of Frankenberg et al. (2011a) and Guanter et al. (2007).

Similar seasonal variation in scaled-F is seen by both sensors as well as EVI, namely, higher Northern Hemisphere values in July versus higher values in the Southern Hemisphere in December. Similar spatial patterns are shown in scaled-F by both SCIAMACHY and GOSAT, such as low values over central Brazil in July and over the northeast of Brazil in December. These variations in GOSAT and SCIAMACHY scaled-F are consistent with a vegetation source such as fluorescence. Like the EVI, a retrieved fluorescence signal (scaled by incoming PAR) is sensitive to the amount of green biomass contained within the sensor field-of-view or fractional amount of intercepted PAR.

Subtle differences in spatial variations are shown between GOSAT- and SCIAMACHY-derived scaled-F. SCIAMACHY shows somewhat lower values at high northern latitudes in the boreal summer as compared with tropical regions. There could be several reasons for this if the primary source of the SCIAMACHY signal is vegetation fluorescence as is presumably the case for the GOSAT observations. Firstly, there may be remaining errors due to instrumental effects. Secondly, SCIAMACHY and GOSAT observations are made at different local times; SCIAMACHY observations are made near 10:00 LT while those of GOSAT are made about $2.5 \mathrm{~h}$ later, just after noon. The shapes of the fluorescence spectra may differ for different types of vegetation as well as different magnitudes and spectral shapes of the incoming solar light. For example, more UV light is absorbed in relatively clear skies at the surface in the tropics where total column ozone and SZAs are low. Plants at these latitudes have more photo-protective mechanisms in place that may produce different fluorescent spectral responses. Compounds within the vegetation besides chlorophyll $a$ may alter the spectral dependence of fluorescence. Finally, canopy structure may influence the fluorescence spectra. Multiple scattering within a deep canopy may enhance fluorescence, producing a different spectral response than a sparse canopy (Rosema et al., 1991).

Figure 9 shows monthly climatologies of scaled-F and $\rho \cos (\mathrm{SZA})$ (proportional to radiance) derived from over $8 \mathrm{yr}$ of SCIAMACHY data (January 2003-December 2011, every other month, gridded at $0.5^{\circ} \times 0.5^{\circ}$ resolution) and EVI 

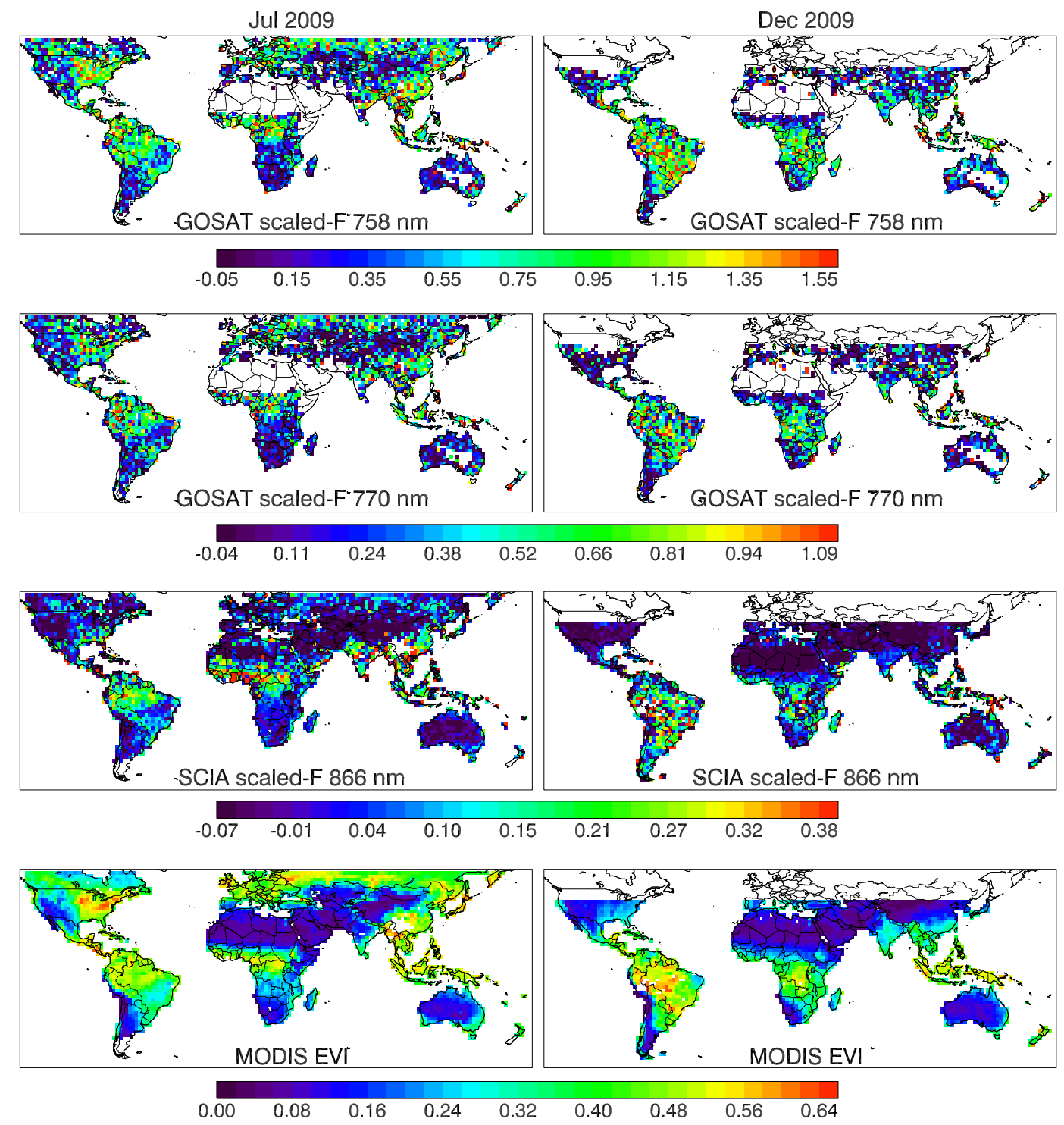

Fig. 8. Derived monthly averages for July (left panels) and December (right panels) 2009; first(second) row: fluorescence scaled by cos(SZA) (scaled-F) (unitless) from GOSAT 758 (770) nm; Third row: scaled-F from SCIAMACHY $866 \mathrm{~nm}$; bottom row: Aqua MODIS enhanced vegetation index (EVI)

from Aqua MODIS (August 2002-July 2011 at the same spatial resolution) for comparison. An animated version of the SCIAMACHY scaled-F climatology is available in the supplemental material. The general spatial and temporal patterns from SCIAMACHY scaled-F are similar to EVI and consistent with fluorescence related to vegetation. Note that we show scaled-F here for solar zenith angles up to $80^{\circ}$. In the winter hemisphere at the highest latitudes shown, scaled-F originating from a terrestrial source is likely to be overestimated owing to atmospheric RRS that is not fully accounted for.

Some interesting differences between scaled-F and EVI are shown here as well as in Fig. 8. For example, we see moderate values of EVI over parts of the northeast and southeast US, Europe, and southeast Asia in the late autumn through early spring while scaled-F is close to zero. The values of scaled-F are more distinctly lower over parts of east and northeast Brazil from May through November as compared with the EVI. These differences are further explored in the next subsection.

Scaled-F is shown to be loosely correlated with radiance in vegetated areas. This would be expected if the additive signal at the $\mathrm{Ca}$ II line has a vegetation source. However, there are also areas of high radiance with low $\bar{F}$ such as over the Sahara and parts of the Saudi Arabian peninsula. This demonstrates that the additive signal is not entirely related 

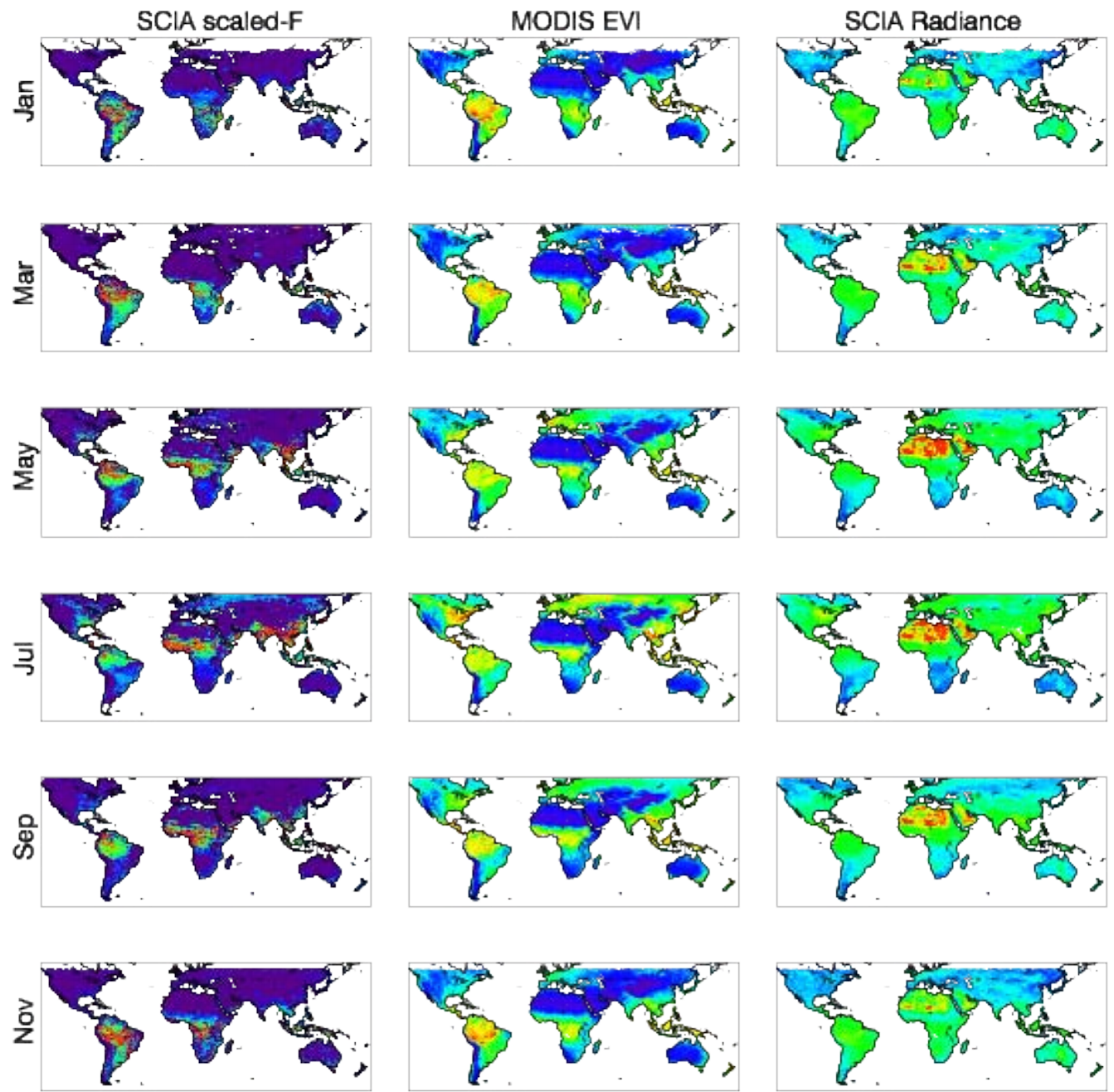

$-0.050 .010 .070 .140 .200 .260 .320 .380 .450 .000 .080 .160 .240 .320 .400 .480 .560 .640 .000 .060 .110 .170 .220 .280 .340 .390 .45$

Fig. 9. Monthly mean scaled-F (left panel) and $\rho \cos (\mathrm{SZA})$, proportional to radiance (right), derived from $8+\mathrm{yr}$ of SCIAMACHY data gridded at $0.5^{\circ} \times 0.5^{\circ}$ resolution and gridded EVI from $9 \mathrm{yr}$ of Aqua MODIS at the same spatial resolution (middle panel) for every other month January through November (top to bottom panels).

to radiance as might be the case if the signal was entirely due to instrumental artifacts. This is also consistent with a vegetation source for the $866 \mathrm{~nm}$ additive signals. Finally, we note that the retrieved value of scaled-F for SCIAMACHY depends upon satellite viewing geometry (see Appendix C for details).

\subsection{Seasonal variations in SCIAMACHY and GOSAT scaled-F and EVI}

In Fig. 11, we examine the climatological seasonal cycle of scaled-F from both SCIAMACHY and GOSAT as well as EVI over several geographic regions shown in Fig. 10. For clarity, GOSAT 770 (758) nm values are reduced by constant factors of 2.25 (4.5). We show examples for several different biome types, using the same vertical range in all panels to highlight differences between scaled-F and EVI for the different regions and vegetation types. A full $8 \mathrm{yr}$ time series for three of the regions with substantial seasonal cycles is shown in Appendix C.

Over the deciduous broadleaf forests of the northeast US (Fig. 11, panel 1), SCIAMACHY scaled-F shows seasonal variations similar to those of GOSAT. SCIAMACHY values in this region are proportionally smaller than GOSAT as compared with the other panels. Like scaled-F, the EVI shows a sharp rise starting around May and a decline starting in September. For evergreen needleleaf (pine) forests in the southeast US (panel 2), seasonal variations are similar for GOSAT scaled-F and EVI. SCIAMACHY scaled-F also shows a later springtime rise and and earlier autumn decline. 


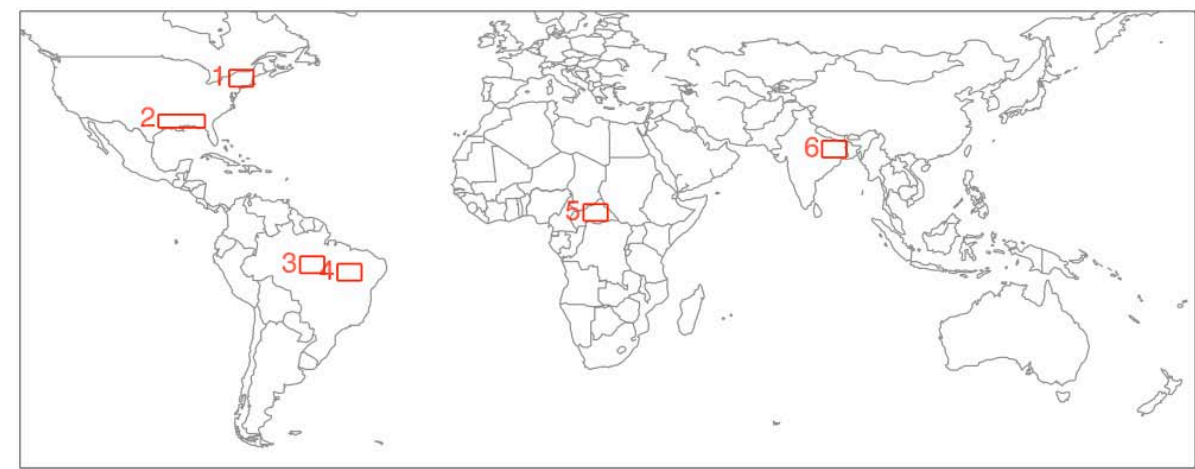

Fig. 10. Regions used for calculating seasonal cycles shown in Fig. 11.
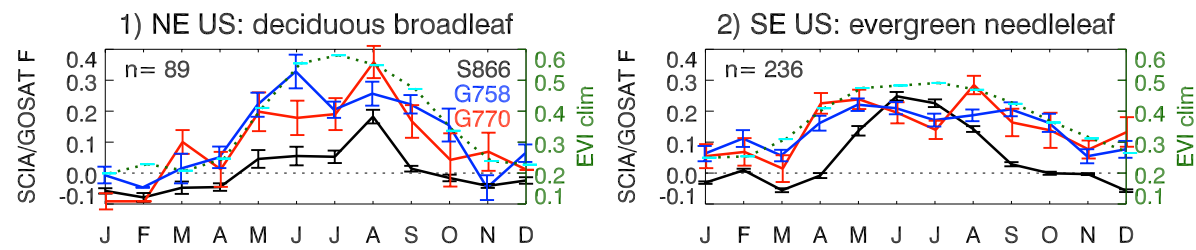

3) C.Amazon: evergreen broadleaf

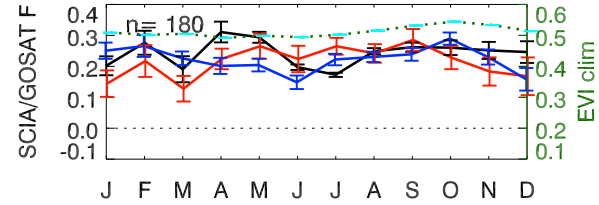

4) NE Brazil: grass + mixed forest

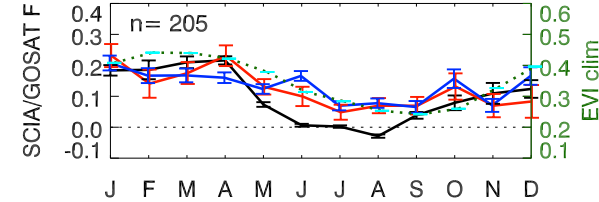

5) C.Africa: woody savannas
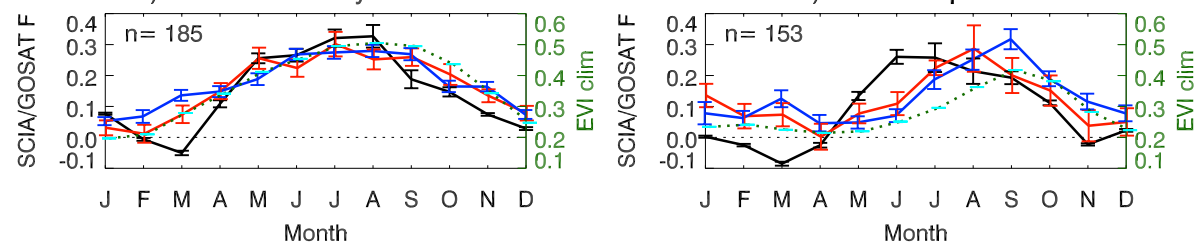

Fig. 11. Seasonal cycles derived for the regions shown in the Fig. 10 map, using $0.5^{\circ} \times 0.5^{\circ}$ gridbox monthly means within the indicated region and with the dominant vegetation type as listed: Black solid line: scaled-F derived from SCIAMACHY (left axis, unitless) and scaled GOSAT (red: $770 \mathrm{~nm}$ scaled by 2.25 ; blue $758 \mathrm{~nm}$ scaled by 4.5 ); vertical bars indicate error of the mean; Green dotted line: MODIS Enhanced Vegetation Index (EVI, right axis, unitless). The numbers indicated are the number of monthly mean $0.5^{\circ} \times 0.5^{\circ}$ gridboxes used in each plot.

For these and many other moderate to high latitude regions, values of the EVI have minima between 0.2 and 0.5 during winter months, while scaled-F is near zero.

In the heavily forested areas of the central Amazon (panel 3), both the EVI and scaled-F remain relatively high year round. This contrasts sharply with shrubland over northeast Brazil (panel 4) at similar latitudes. Here, scaled-F and EVI are low in July through September following the greenup when scaled-F and EVI are high in January through April.

The savannas of central Africa (panel 5) have a distinct and similar seasonal cycle in scaled-F and EVI. Scaled-F from SCIAMACHY shows an earlier peak than that of GOSAT over croplands of India (panel 6). GOSAT scaled-F also peaks somewhat earlier than EVI. The differences between
scaled-F and EVI shown here remain unexplained; it is hoped that future studies will focus on this area to discern whether these differences stem from algorithmic/instrumental artifacts or a geophysical effect.

Although we have shown some differences between EVI and scaled-F, the similarity of the SCIAMACHY and GOSAT scaled-F temporal and spatial variations and the comparisons with EVI appear to be consistent with a major source of the SCIAMACHY scaled-F signals linked to vegetationi fluorescence. The spatial and temporal patterns are not consistent with fire as a dominant source, though we note that fires may contribute to the observed signals. 


\subsection{Filling-in not consistent with vegetation fluorescence}

We note filling-in (retrieved as $\bar{F}$ ) at $866 \mathrm{~nm}$ over parts of the Sahara desert (most apparent in May-September) and the Saudi Arabian peninsula where vegetation is sparse and a significant signal from chlorophyll fluorescence is not expected. We also note some negative filling-in values over these regions that have high radiances values. The memory effect of SCIAMACHY may contribute to these features as radiances at $866 \mathrm{~nm}$ show sometimes large gradients over these areas and our filtering scheme may not have completed removed all affected pixels. The SCIAMACHY memory effect may also affect the reference spectra, particularly for high values of radiance that correspond to the bright cloudy data over ocean. In addition, residual filling-in over the brightest areas may not have been well characterized by the cloudy ocean spectra. Cloudy spectra with high radiance values occur primarily in deep and frontal convection where cloud pressures are low. This may lead to an underestimation of filling-in from RRS when these spectra are used as a reference and thus over-estimation of the residual filling-in from terrestrial sources.

Filling-in over barren regions may also be produced by luminescent minerals in soil and/or rock. Mineral detection was a primary goal of early measurements using the Fraunhofer line discriminator method (e.g., Hemphill and Vickers, 1966; Watson, 1981; Stacy et al., 1984; Hemphill et al., 1988). There are many types of minerals with impurities that luminesce when excited by UV and visible light (Gaft et al., 2005). For example, samples of fluorite $\left(\mathrm{CaF}_{2}\right)$ containing $\mathrm{Nd}^{3+}$ (Neodymium) centers show laser-induced luminescence with peaks at 866 and $795 \mathrm{~nm}$ (Gaft et al., 2005). Similarly, Dy ${ }^{3+}$ (Dysprosium) centers give narrow peaks at 765 and $778 \mathrm{~nm}$.

\section{Conclusions and ongoing work}

Our simulations indicate that terrestrial fluorescence fillingin of the $866 \mathrm{~nm}$ Ca II line can be detected using hyperspectral instruments (spectral resolutions of the order of tenths of a nm) such as SCIAMACHY if the fluorescence at this wavelength is of the order of $0.1-0.2 \mathrm{~mW} \mathrm{~m}^{-2} \mathrm{~nm}^{-1} \mathrm{sr}^{-1}$. Laboratory measurements of vegetation fluorescence excited by broad-spectrum light indicate that such values are possible. After corrections for instrumental artifacts, we retrieved an additive signal over land at $866 \mathrm{~nm}$ with SCIAMACHY. The magnitude of the derived additive signal at $866 \mathrm{~nm}$ is similar to that of our solar-simulator laboratory measurements. The spatial and temporal patterns of the detected additive signals at $866 \mathrm{~nm}$ are consistent with a vegetation source; they are similar to those of EVI and those derived from additive signals at 770 and $758 \mathrm{~nm}$ where fluorescence from chlorophyll $a$ in vegetation is stronger and expected to be the primary source of the signals. Further laboratory and ground-based studies are needed to confirm that the additive signal retrieved at $866 \mathrm{~nm}$ is indeed primarily due to vegetation fluorescence. Measurements of fluorescence and reflectance spectra for a variety of vegetation types, canopy structures, illumination, and environmental conditions will help to improve the interpretation of satellite-derived additive signals shown here. Additional sources of the additive signals include unaccounted-for rotational-Raman scattering in the atmosphere, fluorescence from minerals in rock and soil, and emission from flaming fires and volcanoes.

Owing to the large number of observations collected over more than $8 \mathrm{yr}$ of operation, SCIAMACHY data can be averaged to provide climatological spatial patterns of $\bar{F}$ at a higher resolution than is possible with the current set of GOSAT observations, even though the intrinsic spatial resolution of SCIAMACHY is lower than that of GOSAT. Although the derived spatial patterns and seasonal cycles in scaled-F are similar to those of the MODIS EVI, important differences between scaled-F and EVI are noted. For example, a more distinct shut-off of activity in winter and dry months is shown in scaled-F in some areas as compared with EVI, which could improve estimates of the length of the physiologically-active growing season.

More work needs to be done to further refine $\bar{F}$ retrievals from satellite instruments that were not designed to measure small additive signals. Owing to the extremely small $\bar{F}$ signal derived from instruments that have relatively large systematic errors, our reported absolute values and tempo$\mathrm{ral} / \mathrm{spatial}$ variations may still contain residual errors. However, the approach we developed appears to be capable of detecting and correcting for complex, time-varying instrumental artifacts.

In addition, more research is needed to fully exploit these data within global carbon models and other applications. For example, the influences of canopy structure and other parameters, such as chlorophyll content, need to be further investigated in order to understand their effect on large field-ofview satellite data (e.g., Rosema et al., 1991; Louis et al., 2005; Meroni and Colombo, 2006; Middleton et al., 2008; van der Tol et al., 2009; Zarco-Tejada et al., 2009; Rascher et al., 2009; Damm et al., 2010). It has been suggested that when vegetation is not under stress and the variations in fluorescence yield are small, fluorescence flux from the $740 \mathrm{~nm}$ emission peak, that is affected by reabsorption of emittance from the red peak, is driven primarily by PAR absorption (Moya et al., 2004). Another important factor is that the ratio of fluorescence from the 740 and $680 \mathrm{~nm}$ peak emission features expresses information about photosynthetic function and chlorophyll content (e.g., Lichtenthaler, 1987; Gitelson et al., 1999; Saito et al., 1998; Louis et al., 2005) and function (e.g., Middleton et al., 1996). Therefore, additional measurements of fluorescence at other wavelengths will be useful for retrieving more complete spectral emission curves that enable improved relationships to vegetation function. In order 
to more fully exploit satellite-derived fluorescence measurements for deriving relationships with key carbon-related parameters such as gross primary production (GPP) or light-use efficiency (LUE), fluorescence retrievals should be combined with other observable quantities such as reflectance-based vegetation indices including the narrow band index based on two green bands, the PRI (Daumard et al., 2010; Middleton et al., 2011).

The upcoming launch of the Orbiting Carbon Observatory-2 (OCO-2) (Crisp et al., 2004) will facilitate the use of solar Fraunhofer lines for fluorescence retrievals at wavelengths near the $\mathrm{O}_{2}$-A band (Frankenberg et al., 2011a) and provide more opportunities to improve fluorescence measurements in the NIR region. The FLuorescence EXplorer (FLEX) (Rascher, 2007; European Space Agency, 2008), an ESA Explorer 8 Mission selected for Phase A/B1 in early 2011, plans to utilize the $\mathrm{O}_{2}$-A and B bands for chlorophyll fluorescence retrievals (Guanter et al., 2010) and other spectral information across the visible-NIR spectrum. FLEX would also measure fluorescence at a higher spatial resolution than current satellite sensors that were not designed or optimized for fluorescence retrievals.

\section{Appendix A}

\section{Instrumental effects in SCIAMACHY data that may produce false filling-in}

\section{A1 Memory effect}

In channels $1-5$, it was found that the signal deviates from a linear response. The deviation depends upon the signal level of the previous readout. It also depends on the signal level including analog offset and dark current. Since there is a dependence on the previous signal for a large range of detector fillings, artificial spectral features can be introduced into the measurements.

We found systematic biases in Fraunhofer line filling as a function of position within a block of nadir measurements. The first several positions (following the limb-viewing mode) have the largest biases. Because of repeating orbital patterns, if this effect is not accounted for, a cross-track striping will be present in the observed filling-in, even after averaging a month of data.

\section{A2 Dark current}

There are two components that contribute to the dark signal in channels 1-5: the analog offset and the leakage current. The former does not depend on integration time while the latter does. We found different biases in the filling-in for the two primary pixel exposure times (PETs) used for nadir measurements in channels 4 and 5 that may be a result of unaccounted-for dark signals.

\section{A3 Wavelength calibration and undersampling}

Due to the Doppler and other effects, there are small wavelength shifts in Earth spectra with respect to the measured solar spectra. We found that these wavelength shifts vary systematically with latitude. Wavelength shifts between observed and reference spectra must be accurately accounted for when deriving a relatively small filling-in signal.

\section{A4 Stray light}

Stray light may be classified as two types: spectral and spatial. Both of these can distort observed spectra. Spatial stray light mainly affects the limb measurements of SCIAMACHY, but may also produce errors in a fluorescence retrieval in the nadir mode. Spectral stray light may be caused by diffuse reflection that adds signal to all detector pixels in a given channel, thus mimicking fluorescence. The largest expected uniform stray light fraction in SCIAMACHY is $0.14 \%$ (Lichtenberg et al., 2006).

So-called "ghost" stray light is caused by reflection from one wavelength to another. It does not add signal to all pixels equally, but can distort the spectrum. The correction method is accurate to around $25 \%$, leaving at most $1 \%$ stray light in the spectrum.

\section{A5 Calibration}

Various issues with SCIAMACHY's radiometric calibration are discussed by Lichtenberg et al. (2006). These may affect the absolute values of derived fluorescence. In addition to radiometry, the applied calibration scheme may introduce spectral features and thus produce false filling-in.

\section{Appendix B}

\section{Temporal and spatial variations in GOSAT cloudy ocean spectra}

Here, we show temporal and latitudinal variations in the filling-in over cloudy ocean scenes caused primlarily by the zero-level offset problem in GOSAT data. Figure B1 shows filling-in as a function of normalized radiance binned at intervals of 0.05 . We compute the filling-in for diagnostic purposes only; it is more straight-forward to interpret and compare with previous works than reference spectra. The overall dependence of filling-in on radiance is similar to the dependence derived using data over Antarctica by Frankenberg et al. (2011b). However, here we show that the filling-in at low to moderate radiances for both polarizations varies with both time and latitude. 

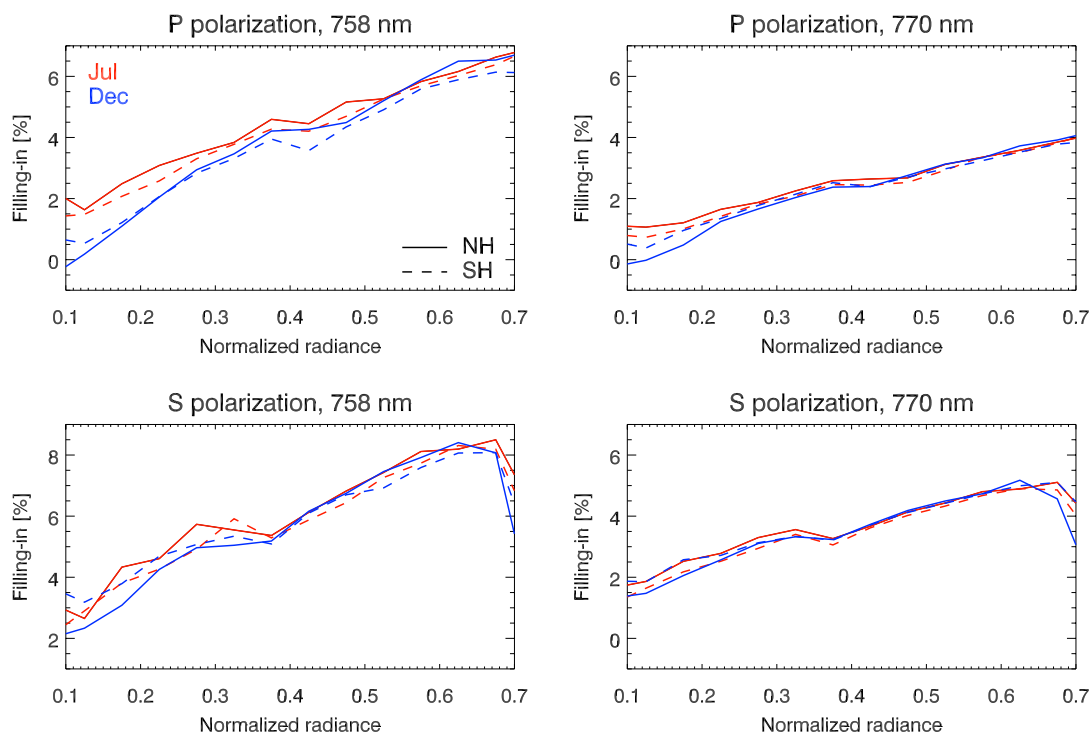

Fig. B1. Diagnostic filling-in derived over cloudy ocean pixels versus $\rho \cos ($ SZA) derived for GOSAT 758 (770) nm in left (right) panels for $\mathrm{P}(\mathrm{S})$ polarization in top (bottom) panels for July and December 2009 averaged over normalized radiance bins of 0.05 and separately for Northern (Southern) Hemispheres shown by solid (dashed) lines.

\section{Appendix C}

\section{Parameters related to uncertainty in climatological monthly-mean scaled-F from SCIAMACHY}

Figure $\mathrm{C} 1$ shows examples of three mapped statistical parameters (number of observations averaged, standard deviation, and standard error) for SCIAMACHY gridded data in January and July. All parameters correspond to monthly data obtained over the years 2003-2011. These data show that the standard deviations are roughly consistent with those that would be expected from instrumental noise. Additional dispersion in scaled-F may result from variations in aerosol and cloud cover, actual variations in scaled-F owing to environmental stress on vegetation, and residual uncorrected systematic errors. For most areas, the standard errors are substantially smaller owing to averaging of a number of observations taken over the $8 \mathrm{yr}$ time period.

For reference, Fig. C2 shows the entire time series of monthly-mean scaled-F for 3 of the boxes in Fig. 10 where there is a significant seasonal cycle. Inter-annual variability is seen in these data. Evidence of long-term trends due to either geophysical changes or calibration drift is not obvious. Future studies will focus on determining whether the inter-annual variations shown can be related to geophysical parameters such as environmental stress on vegetation. Because the systematic errors that we attempt to correct for can represent a large fraction of the observed additive signal, we do not rule out the possibility that at least some of the interannual variations are due to uncorrected systematic errors. That is why we focus on climatological averages in this work.
Finally, we note that there is a dependence of the SCIAMACHY retrieved additive signal on viewing geometry. Figure $\mathrm{C} 3$ shows scaled-F retrieved on the east and west sides of the SCIAMACHY swath, the difference between the two, and the east to west side swath difference of radiance for the July climatology. The regions with large cross-track asymmetry in scaled-F vary with season (not shown). The scaled-F angular dependence shows some similarities to that of radiance, but also shows some differences. Guanter et al. (2012) also report on viewing-angle dependence of retrieved fluorescence from GOSAT. We did not obtain a statistically robust dependence on viewing angle for GOSAT scaled-F retrievals. The observed cross-track asymmetry in SCIAMACHY scaled-F may be related to differences in the amounts of absorbed PAR and fluorescence escaping the canopy for different viewing geometries, related to leaf orientation and canopy effects. The results shown here are preliminary; further examination of these effects will be the topic of future studies.

\section{Supplementary material related to this article is available online at: http://www.atmos-meas-tech.net/5/ 809/2012/amt-5-809-2012-supplement.zip.}

Acknowledgements. Funding for this work was provided by the NASA Carbon Cycle Science program (NNH10DA001N) managed by Diane E. Wickland and Richard Eckman. The authors are indebted to C. Retscher for assistance with the satellite data sets, particularly the SCIAMACHY data. We gratefully acknowledge the European Space Agency, the GOSAT project, and the MODIS data processing team for making available the SCIAMACHY, 

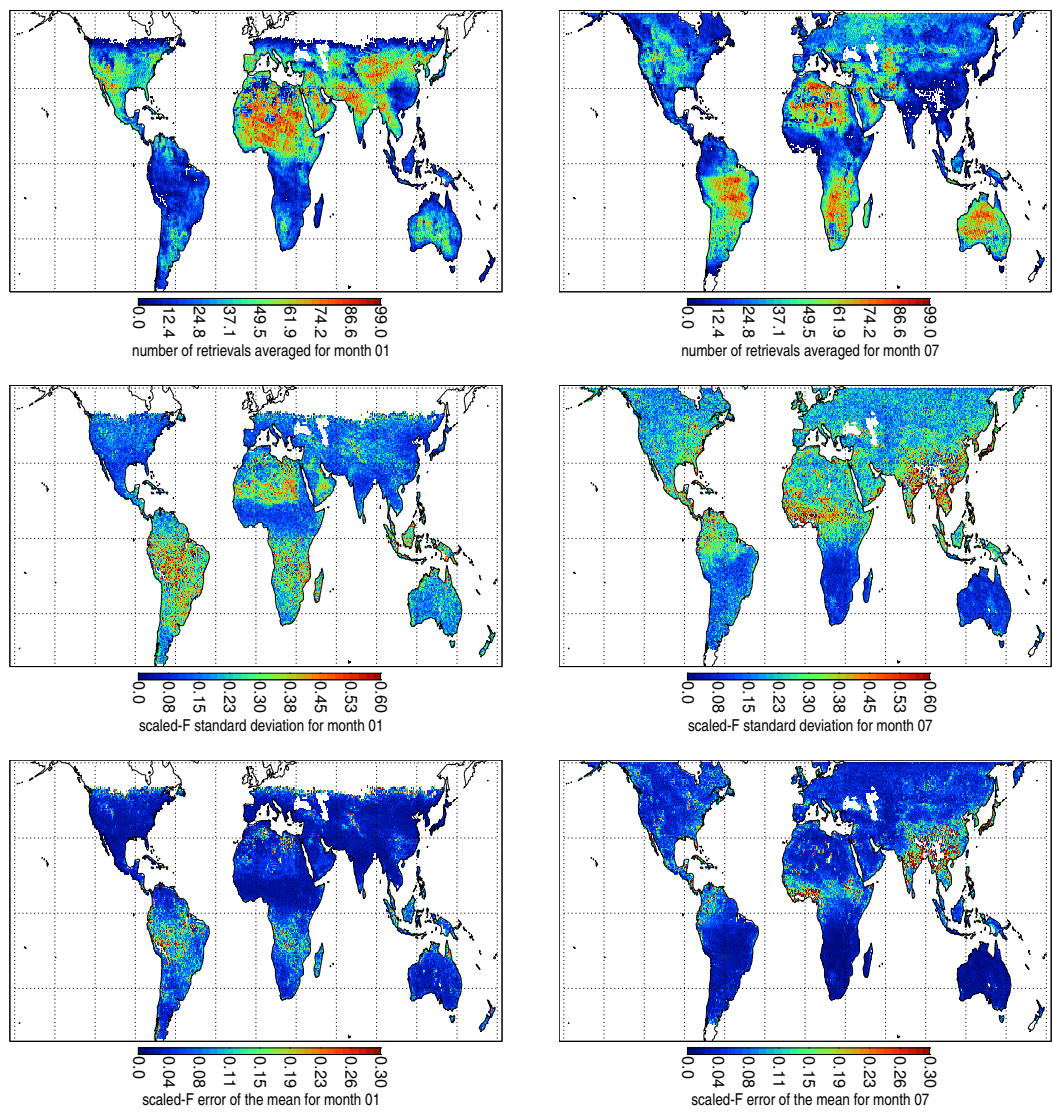

Fig. C1. Number of SCIAMACHY observations passing our quality control filters (top panels), the gridbox standard deviations (middle panels), and standard errors (bottom panels) for the January climatological average over years 2003-2011 (left panels) and the same for July (right panels).
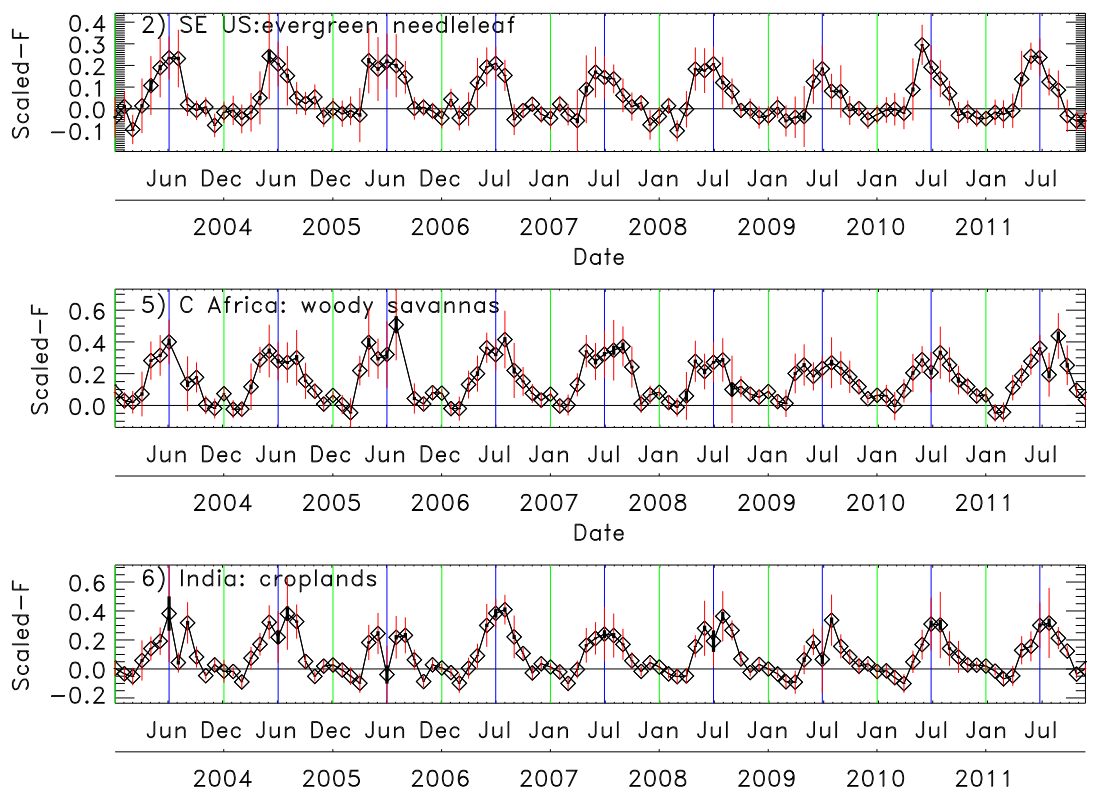

Fig. C2. Monthly mean scaled-F as derived from SCIAMACHY versus time over the period January $2003-$ December 2011 for 3 of the boxes shown in Fig. 10 as indicated. Standard deviations are shown with red vertical bars and standard errors are shown with thick black vertical bars (sometimes too small to be noticeable). 


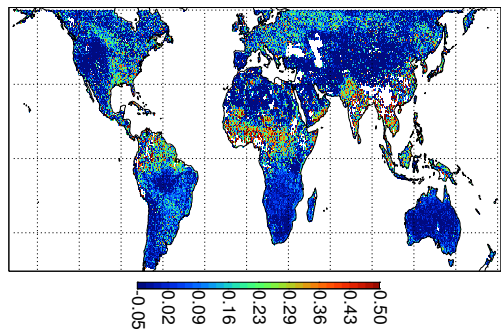

east (forward scatter) side of swath for month month 07

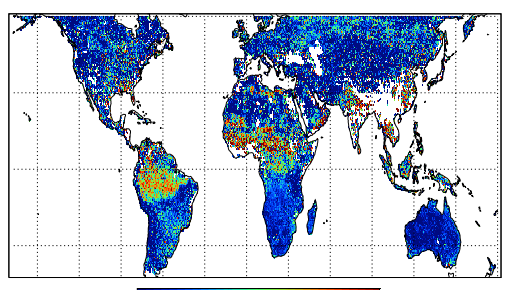

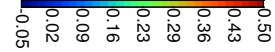

west (back scatter) side of swath for month month 07
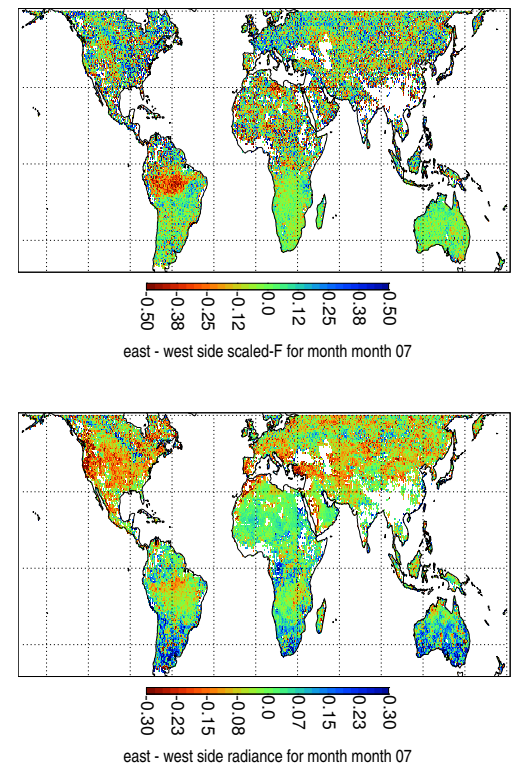

Fig. C3. Monthly mean scaled-F as derived from SCIAMACHY for observations on the left side of the swath (top left panel) and right side (bottom left panel) for July averaged over the years 2003-2011. The difference is shown in the top right along with the similarly derived difference in radiance (bottom right panel).

GOSAT, and MODIS data, respectively, used here. We also thank L. Guanter and an anonymous reviewer for comments that helped to improve the manuscript and W. Philpot, W. Cook, K. F. Huemmrich, Y.-B. Cheng, Q. Zhang, J. Mao, C. Weaver, D. Crisp, and A. da Silva for helpful discussions/correspondence.

Edited by: M. Weber

\section{References}

Amoros-Lopez, J., Gomez-Chova, L., Vila-Frances, J., Alonso, L., Calpe, J., Moreno, J., and del Valle-Tascon, S.: Evaluation of remote sensing of vegetation fluorescence by the analysis of diurnal cycles, Int. J. Remote Sens., 29, 5423-5436, 2008.

Burrows, J., Vountas, M., Hang, H., Chance, K., Marquard, L., Muirhead, K., Platt, U., Richter, A., and Rozanov, V.: Study of the Ring effect, ESA final report, 1996.

Campbell, P. K. E., Middleton, E. M., Corp, L. A., and Kim, M. S.: Contribution of chlorophyll fluorescence to the apparent vegetation reflectance, Sci. Total Environ., 404, 433-439, 2008.

Chance, K. and Kurucz, R. L.: An improved high-resolution solar reference spectrum for Earth's atmosphere measurements in the ultraviolet, visible, and near infrared, J. Quant. Spectrosc. Ra., 111, 1289-1295, 2010.

Chance, K., Kurosu, T. P., and Sioris, C. E.: Undersampling correction for array detector-based satellite spectrometers, Appl. Optics, 44, 1296-1304, 2005.

Chance, K. V. and Spurr, R. J. D.: Ring effect studies: Rayleigh scattering, including molecular parameters for rotational Raman scattering, and the Fraunhofer spectrum, Appl. Optics, 36, 52245230, 1997.
Chappelle, E. W. and Williams, D. L., Laser-induced fluorescence (LIF) from plant foliage, IEEE T. Geosci. Remote, GE-25, 726736, 1987.

Chappelle, E. W., Wood, F. M., McMurtrey, J. E., and Newcomb, W. W.: Laser-induced fluorescence of green plants, 1: A technique for the remote detection of plant stress and species differentiation, Appl. Optics, 23, 134-138, 1984.

Corp, L. A., McMurtrey, J. E., Middleton, E. M., Mulchi, C. L., Chappelle, E. W., and Daughtry, C. S. T.: Fluorescence Sensing Systems: In vivo detection of biophysical variations in field corn due to nitrogen supply, Remote Sens. Environ., 86, 470479, 2003.

Corp, L. A., Middleton, E. M., McMurtrey, J. E., Campbell, P. K. E., and Butcher, L. M.: Fluorescence sensing techniques for vegetation assessment, Appl. Optics, 45, 1023-1033, 2006.

Crisp, D.: The Orbiting Carbon Observatory (OCO) mission, Adv. Space Res., 34, 700-709, 2004.

Damm, A., Elbers, J., Erler, A., Giolis, B., Hamdi, K., Hutjes, R. W. A., Kosvancova, M., Meroni, M., Migliettas, F., Moersch, A., Moreno, J., Schickling, A., Sonnenschein, R., Udelhoven, T., Van Der Linden, S., Hostert, P., and Rascher, U.: Remote sensing of sun-induced fluorescence to improve modeling of diurnal courses of gross primary production (GPP), Global Change Biol., 16, 171-186, doi:10.1111/j.1365-2486.2009.01908.x, 2010.

Danichkin, S. A., Eliseev, A .A., Popova, T. N., Ravodina, O. V., and Stenina, V. V.: Raman scattering parameters for gas molecules (Review), J. Appl. Spectrosc., 35, 1057-1066, 1982.

Daumard, F., Champagne, S., Fournier, A., Goulas, Y., Ounis, A., Hanocq, J.-F., and Moya, I.: A field platform for continuous measurement of canopy fluorescence, IEEE T. Geosci. Remote, 48, 3358-3368, 2010. 
DLR - Deutsches Zentrum fur Luft- und Raumfahrt: SCIAMACHY Level 1b-1c processing The SciaL1c Command-line tool software user's manual, ENV-SUM-DLR-SCIA-0071, Issue $6.0,2006$.

Edner, H., Johansson, J., Svanberg, S., and Wallinder, E.: Fluorescence lidar multicolor imaging of vegetation, Appl. Optics, 33, 2471-2479, 1994.

European Space Agency:. ESA SP-1313/4 Candidate Earth Explorer Core Missions - Reports for Assessment: FLEX - FLuorescence EXplorer, available at: http://esamultimedia.esa.int/ docs/SP1313-4_FLEX.pdf., published by ESA Communication Production Office, Noordwijk, The Netherlands, 2008.

Fenner, W. R., Hyatt, H. A., Kellam, J. M., and Porto, S. P. S.: Raman cross section of some simple gases, J. Opt. Soc. Am., 63, 73-77, 1973.

Flexas, J., Escalona, J. M., Evain, S., Gulías, J., Moya, I., Osmond, C. B., and Medrano, H.: Steady-state chlorophyll fluorescence (Fs) measurements as a tool to follow variations of net $\mathrm{CO}_{2}$ assimilation and stomatal conductance during water-stress in $\mathrm{C}_{3}$ plants, Physiologia Plantarum, 114, 231-240, 2002.

Frankenberg, C., Butz, A., and Toon, G. C.: Disentangling chlorophyll fluorescence from atmospheric scattering effects in $\mathrm{O} 2 \mathrm{~A}$ band spectra of reflected sun-light, Geophys. Res. Lett., 38, L03801, doi:10.1029/2010GL045896, 2011a.

Frankenberg, C., Fisher, J. B., Worden, J., Badgley, G., Saatchi, S. S., Lee, J.-E., Toon, G. C., Butz, A., Jung, M., Kuze, A., and Yokota, T.: New global observations of the terrestrial carbon cycle from GOSAT: Patterns of plant fluorescence with gross primary productivity, Geophys. Res. Lett., 38, L17706, doi:10.1029/2011GL048738, 2011b.

Gaft, M., Reisfeld, R., and Panczer, G.: Modern luminescence spectroscopy of minerals and materials, Spring-Verlag, Berlin, Heidelberg, 356 pp., 2005.

Gitelson, A. A., Buschmann, C., and Lichtenthaler, H. K.: The chlorophyll fluorescence ratio $F_{735} / F_{700}$ as an accurate measure of chlorophyll content in plants, Remote Sens. Environ., 69, 296$302,1999$.

Gottwald, M., Bovensmann, H., Lichtenberg, G., Noel, S., von Bargen, A., Slijkhuis, S., Piters, A., Hoogeveen, R., von Savigny, C., Buchwitz, M., Kokhanovsky, A., Richter, A., Rozanov, A., Holzer-Popp, T., Bramstedt, K., Lambert, J.-C., Skupin, J., Wittrock, F., Schrijver, H., and Burrows, J. P.: SCIAMACHY, Monitoring the Changing Earth's Atmosphere, Published by DLR and Springer, doi:10.1007/978-90-481-9896-2, 2006.

Guanter, L., Alonso, L., Gómez-Chova, L., Amorós-López, J., VilaFrancés, J., and Moreno, J.: Estimation of solar-induced vegetation fluorescence from space measurements, Geophys. Res. Lett., L08401, doi:10.1029/2007GL029289, 2007.

Guanter, L., Alonso, L., Gómez-Chova, L., Meroni, M., Preusker, R., Fischer, J., and Moreno, J.: Developments for vegetation fluorescence retrieval from spaceborne high-resolution spectrometry in the $\mathrm{O}_{2}$-A and $\mathrm{O}_{2}$-B absorption bands, J. Geophys. Res., 115, D19303, doi:10.1029/2009JD013716, 2010.

Guanter, L., Frankenberg, C., Dudhia, A., Lewis, P. E., GómezDans, J., Kuze, A., Suto, H., and Grainger, R. G.: Retrieval and global assessment of terrestrial chlorophyll fluorescence from GOSAT space measurements, Remote Sens. Environ., 121, 236251,2012
Heise, H. M. and Schrotter, H. W.: Rotation-vibration spectra of gases, Infrared and raman Spectroscopy, Methods and Applications, VCH, Weinheim, Chapt. 4.3, 253-297, 1995.

Hemphill, W. R. and Vickers, R.: Geological studies of the Earth and planetary surfaces of ultraviolet absorption and stimulated luminescence, NASA Tech. Lett. NASA-33, Washington, DC, USA, 1966.

Hemphill, W. R., Tyson, R. M., and Theisen, A. F.: Spectral luminescence properties of natural specimens in the scheelitepowellite series, and an assessment of their detectivity with an airborne Fraunhofer line discriminator, Econ. Geol., 83, 637646,1988

Huete, A. R., Didan, K., Miura, T., Rodriguez, E. P., Gao, X., and Ferreira, L. G.: Overview of the radiometric and biophysical performance of the MODIS vegetation indices, Remote Sens. Environ., 83, 195-213, 2002.

Joiner, J., Yoshida, Y., Vasilkov, A. P., Yoshida, Y., Corp, L. A., and Middleton, E. M.: First observations of global and seasonal terrestrial chlorophyll fluorescence from space, Biogeosciences, 8, 637-651, doi:10.5194/bg-8-637-2011, 2011.

Joiner, J., Vasilkov, A. P., Gupta, P., Bhartia, P. K., Veefkind, P., Sneep, M., de Haan, J., Polonsky, I., and Spurr, R.: Fast simulators for satellite cloud optical centroid pressure retrievals; evaluation of OMI cloud retrievals, Atmos. Meas. Tech., 5, 529-545, doi:10.5194/amt-5-529-2012, 2012.

Kuze, A., Suto, H., Nakajima, M., and Hamazaki, T.: Thermal and near infrared sensor for carbon observation Fourier-transform spectrometer on the Greenhouse Gases Observing Satellite for greenhouse gases monitoring, Appl. Optics, 48, 6716-6733, 2009.

Kuze, A., O’Brien, D. M., Taylor, T. E. , Day, J. O., O’Dell, C., Kataoka, F., Yoshida, M., Mitomi, Y., Bruegge, C., Pollock, H., Basilio, R., Helmlinger, M., Matsunaga, T., Kawakami, S., Shiomi, K., Urabe, T., and Suto, H.: Vicarious calibration of the GOSAT sensors using the Railroad Valley desert playa, IEEE T. Geosci. Remote, 49, 1781-1795, doi:10.1109/TGRS.2010.2089527, 2011a.

Kuze, A., Suto, H., Shiomi, K., and Nakajima, M.: GOSAT TANSO calibration and characterization of 2 years on orbit operation, Proceedings of The 28th International Symposium on Space Technology and Science (ISTS), Okinawa, 2011.

Lichtenberg, G., Kleipool, Q., Krijger, J. M., van Soest, G., van Hees, R., Tilstra, L. G., Acarreta, J. R., Aben, I., Ahlers, B., Bovensmann, H., Chance, K., Gloudemans, A. M. S., Hoogeveen, R. W. M., Jongma, R. T. N., Noël, S., Piters, A., Schrijver, H., Schrijvers, C., Sioris, C. E., Skupin, J., Slijkhuis, S., Stammes, P., and Wuttke, M.: SCIAMACHY Level 1 data: calibration concept and in-flight calibration, Atmos. Chem. Phys., 6, 5347-5367, doi:10.5194/acp-6-5347-2006, 2006.

Lichtenthaler, H. K.: Chlorophyll fluorescence signatures of leaves during the autumnal chlorophyll breakdown, J. Plant Physiol., 131, 101-110, doi:10.1016/j.bbr.2011.03.031, 1987.

Louis, J., Ounis, A., Ducruet, J.-M., Evain, S., Laurila, T., Thum, T., Aurela, M., Wingsle, G., Alonso, L., Pedros, R., and Moya, I.: Remote sensing of sunlight-induced chlorophyll fluorescence and reflectance of Scots pine in the boreal forest during spring recovery, Remote Sens. Environ., 96, 37-48, 2005. 
Lucht, W., Schaaf, C. B., and Strahler, A. H.: An Algorithm for the retrieval of albedo from space using semiempirical BRDF models, IEEE T. Geosci. Remote, 38, 977-998, 2000.

McFarlane, J. C., Watson, R. D., Theisen, A. F., Jackson, R. D., Ehrler, W. L., Pinter, P. J., Idso, S. B., and Reginato, R. J.: Plant stress detection by remote measurement of fluorescence, Appl. Optics, 19, 3287-3289, 1980.

Meroni, M. and Colombo, R.: Leaf level detection of solar induced chlorophyll fluorescence by means of a subnanometer resolution spectroradiometer, Remote Sens. Environ., 103, 438-448, 2006.

Meroni, M., Picchi, V., Rossini, M., Cogliati, S., Panigada, C., Nali, C., Lorenzini, G., and Colombo, R.: Leaf level early assessment of ozone injuries by passive fluorescence and photochemical reflectance index, Int. J. Remote Sens., 29, 5409-5422, 2008.

Meroni, M., Rossini, M., Guanter, L., Alonso, L., Rascher, U., Colombo, R., and Moreno, J.: Remote sensing of solar-induced chlorophyll fluorescence: Review of methods and applications, Remote Sens. Environ., 113, 2037-2051, 2009.

Middleton, E. M., Chappelle, E. W., Cannon, T. A., Adamse, P., and Britz, S. J.: Initial assessment of physiological response to UVB irradiation using fluorescence measurements, J. Plant Physiol., 148, 68-77, 1996.

Middleton, E. M., Corp, L. A., and Campbell, P. K. E.: Comparison of measurements and FluorMOD simulations for solar induced chlorophyll fluorescence and reflectance of a corn crop under nitrogen treatments, Special Issue for the Second International Symposium on Recent Advances in Quantitative Remote Sensing (RAQRSII), Int. J. Rem. Sens., 29, 5193-5213, 2008.

Middleton, E. M., Cheng, Y.-B., Corp, L. A., Huemmrich, K. F., Campbell, P. K. E., Zhang, Q.-Y., Kustas, W. P., and Russ, A. L.: Diurnal and seasonal dynamics of canopy-level solar-induced chlorophyll fluorescence and spectral reflectance indices in a cornfield, Proc. 6th EARSeL SIG Workshop on Imaging Spectroscopy, CD-Rom, 16-19 March, Tel-Aviv, Israel, 12 pp., 2009.

Middleton, E. M., Huemmrich, K. F., Cheng, Y.-B., and Margolis, H. A.: Spectral bio-indicators of photosynthetic efficiency and vegetation stress, in: Hyperspectral Remote Sensing of Vegetation, edited by: Thenkbail, P. S., Lyon, J. G., and Huete, A., Cat. \# K12019, Taylor \& Francis, 2011.

Moya I., Camenen, L. Evain, S., Goulas, Y., Cerovic, Z. G., Latouche, G., Flexas, J., and Ounis, A.: A new instrument for passive remote sensing: 1. Measurements of sunlight-induced chlorophyll fluorescence, Remote Sens. Environ., 91, 186-197, 2004.

Plascyk, J. A. and Gabriel, F. C.: The Fraunhofer Line Discriminator MKII - An airborne instrument for precise and standardized ecological luminescence measurement, IEEE T. Instrum. Meas., 24, 306-313, 1975.

Rascher, U.: FLEX - Fluorescence EXplorer: A remote sensing approach to quantify spatio-temporal variations of photosynthetic efficiency from space, Photosynth. Res., 91, 293-294, 2007.

Rascher, U., Agati, G., Alonso, L., Cecchi, G., Champagne, S., Colombo, R., Damm, A., Daumard, F., de Miguel, E., Fernandez, G., Franch, B., Franke, J., Gerbig, C., Gioli, B., Gómez, J. A., Goulas, Y., Guanter, L., Gutiérrez-de-la-Cámara, Ó., Hamdi, K., Hostert, P., Jiménez, M., Kosvancova, M., Lognoli, D., Meroni, M., Miglietta, F., Moersch, A., Moreno, J., Moya, I., Neininger, B., Okujeni, A., Ounis, A., Palombi, L., Raimondi, V., Schickling, A., Sobrino, J. A., Stellmes, M., Toci, G., Toscano, P.,
Udelhoven, T., van der Linden, S., and Zaldei, A.: CEFLES2: the remote sensing component to quantify photosynthetic efficiency from the leaf to the region by measuring sun-induced fluorescence in the oxygen absorption bands, Biogeosciences, 6, 1181-1198, doi:10.5194/bg-6-1181-2009, 2009.

Rosema, A., Verhoef, W., Schoote, J., and Snel, J. F. H.: Simulating fluorescence light-canopy interaction in support of laserinduced fluorescence measurements, Remote Sens. Environ., 37, 117-130, 1991.

Saito, Y., Kanoh, M., Hatake, K., Kawahara, T. D., and Nomura, A.: Investigation of laser-induced fluorescence of several natural leaves for application to lidar vegetation monitoring, Appl. Optics, 37, 431-437, 1998.

Sioris, C., Courrèges-Lacoste, G. B., and Stoll, M. P.: Filling in of Fraunhofer lines by plant fluorescence: Simulations for a nadirviewing satellite-borne instrument, Geophys. Res. Lett., 108, 4133, doi:10.1029/2001JD001321, 2003.

Spurr, R. J. D., de Haan, J., van Oss, R., and Vasilkov, A. P.: Discrete ordinate radiative transfer in a stratified medium with first order rotational Raman scattering, J. Quant. Spectrosc. Ra., 109, 404-425, 2008.

Stacy, J. E., Breckinridge, J. B., Conel, J. E., and Chrisp, M. P.: Orbital Fraunhofer line discriminator feasibility study, NASA FOIA Request No. 10-JPL-F-01288, Jet Propulsion Laboratory report D-1512, 1984.

Stammes, P., Sneep, M., de Haan, J. F., Veefkind, J. P., Wang, P., and Levelt, P. F.: Effective cloud fractions from the Ozone Monitoring Instrument: Theoretical framework and validation, J. Geophys. Res., 113, D16S38, doi:10.1029/2007JD008820, 2008.

Thuillier, G., Hersé, M., Labs, D., Foujols, T., Peetermans, W., Gillotay, D., Simon, P. C., and Mandel, H.: The solar spectral irradiance from 200 to $2400 \mathrm{~nm}$ as measured by the SOLSPEC spectrometer from the ATLAS and EURECA missions, Solar Phys., 214, 1-22, 2003.

Thuillier, G., Floyd, L., Woods, T. N., Cebula, R., Hilsenrath, E., Hersé, M., and Labs, D.: Solar irradiance reference spectra, in: Solar Variability and its Effect on the Earth's Atmosphere and Climate System, Geophysical Monograph, edited by: Pap, J., Fox, P., Frohlich, C., Hudson, H. S., Kuhn, J., McCormack, J., North, G., Sprigg, W., and Wu, S. T., Vol. 141, American Geophysical Union, Washington, DC, 171-194, 2004.

van der Tol, C., Verhoef, W., and Rosema, A.: A model for chlorophyll fluorescence and photosynthesis at leaf scale, Agr.. Forest Meteorol., 149, 96-105, 2009.

Vasilkov, A. P., Joiner, J., Gleason, J. F., and Bhartia, P. K.: Ocean Raman scattering in satellite backscatter ultraviolet measurements, Geophys. Res. Lett., 29, 1837-1840, 2002.

Watson, R. D.: Airborne Fraunhofer line discriminator surveys in southern California, Nevada, and central New Mexico, Workshop of applications of luminescence techniques to Earth resource studies, in: A Lunar and Planetary Institute Workshop, 10-12 December 1980, edited by: Hemphill, W. R. and Settle, M., Tech Rep. 81-03, LPI, Houston, TX, 28-35, 1981.

Xu, L., Samanta, A., Costa, M. H., Ganguly, S., Nemani, R. R., and Myneni, R. B.: Widespread decline in greenness of Amazonian vegetation due to the 2010 drought, Geophys. Res. Lett., 38, L07402, doi:10.1029/2011GL046824, 2011. 
Yokota, T., Yoshida, Y., Eguchi, N., Ota, Y., Tanaka, T., Watanabe, $\mathrm{H}$., and Maksyutov, S.: Global Concentrations of $\mathrm{CO}_{2}$ and $\mathrm{CH}_{4}$ Retrieved from GOSAT: First Preliminary Results, Sci. Online Lett. Atmos., 5, 160-163, 2009.
Zarco-Tejada, P. J., Berni, J. A. J., Suarez, L., Sepulcre-Cantó, G., Morales, F., and Miller, J. R.: Imaging chlorophyll fluorescence with an airborne narrow-band multispectral camera for vegetation stress detection, Remote Sens. Environ., 113, 1262-1275, 2009 . 